ARTICLE

httpst//doi.org/10.1038/s41467-020-16629-3

\title{
Polyamine regulation of ion channel assembly and implications for nicotinic acetylcholine receptor pharmacology
}

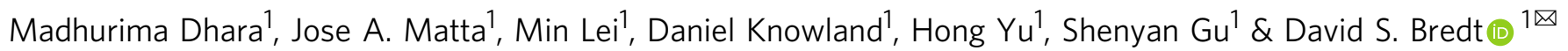

Small molecule polyamines are abundant in all life forms and participate in diverse aspects of cell growth and differentiation. Spermidine/spermine acetyltransferase (SAT1) is the ratelimiting enzyme in polyamine catabolism and a primary genetic risk factor for suicidality. Here, using genome-wide screening, we find that SAT1 selectively controls nicotinic acetylcholine receptor ( $n A C h R)$ biogenesis. SAT1 specifically augments assembly of $n A C h R s$ containing $\alpha 7$ or $\alpha 4 \beta 2$, but not $\alpha 6$ subunits. Polyamines are classically studied as regulators of ion channel gating that engage the nAChR channel pore. In contrast, we find polyamine effects on assembly involve the $n A C h R$ cytosolic loop. Neurological studies link brain polyamines with neurodegenerative conditions. Our pharmacological and transgenic animal studies find that reducing polyamines enhances cortical neuron nAChR expression and augments nicotine-mediated neuroprotection. Taken together, we describe a most unexpected role for polyamines in regulating ion channel assembly, which provides a new avenue for nAChR neuropharmacology.

\footnotetext{
${ }^{1}$ Neuroscience Discovery, Janssen Pharmaceutical Companies of Johnson and Johnson, 3210 Merryfield Row, San Diego, CA 92121, USA.

$凶_{\text {email: dbredt@its.jnj.com }}$
} 
$\mathrm{N}$ euronal nicotinic acetylcholine receptor (nAChR) ion channels mediate behavioral, cognitive and autonomic effects of acetylcholine and addictive properties of nicotine $^{1-6}$. The nAChR family comprises nine alpha $(\alpha 2-10)$ and three beta ( $\beta 2-4)$ subunits that combine to form an array of pentameric cation channels throughout the brain and peripheral nervous systems. The major $\mathrm{nACh}$ receptors in brain are $\alpha 7$ homomers, $\alpha 4 \beta 2$ heteromers, and a6-containing heteromers. These receptors are targets of numerous approved and experimental medicines for diverse conditions including Alzheimer's disease, Parkinson's disease, and neuropathic pain ${ }^{7,8}$.

Whereas nAChRs are compelling drug targets, progress is hampered because most receptor subtypes do not functionally express in the non-neuronal cell lines used for screening ${ }^{9,10}$. We previously identified $\mathrm{NACHO}$, a four-pass transmembrane protein that serves as a client-specific chaperone for assembly of most neuronal nAChRs ${ }^{1-13}$. In brain, NACHO is essential for function of $\alpha 7$ receptors, and additional proteins, Ric- $3^{14}$ and certain Bcl-2 family members ${ }^{15}$, synergize with $\mathrm{NACHO}$ to enhance $\alpha 7$ assembly and surface trafficking. $\mathrm{NACHO}$ also promotes assembly of $\alpha 4 \beta 2$ receptors, though Ric- 3 and Bcl- 2 proteins have minimal impact on $\alpha 4 \beta 2$.

Here, we sought factors that conspire with NACHO to enhance function of $\alpha 4 \beta 2$ receptors, the most abundant $\mathrm{nAChR}$ subtype in brain. These neuronal $\alpha 4 \beta 2$ receptors mediate diverse physiological actions of acetylcholine and underlie nicotine dependence ${ }^{16}$. Genome-wide cDNA screening for protein enhancers of $\alpha 4 \beta 2$ function identified, quite surprisingly, a single standout clone that encodes spermidine/spermine acetyltransferase (SAT1), the rate limiting enzyme for polyamine catabolism. By degrading polyamines, SAT1 promotes $\alpha 4 \beta 2$ function to an even greater extent than does NACHO.

Polyamines are abundant polycations, including spermidine and spermine, that play multiple roles in cell growth, differentiation and survival ${ }^{17}$. The interplay between their synthesis by ornithine decarboxylase-1 (ODC1) and their degradation by SAT1 controls polyamine levels. ODC1 is amongst the most dynamically regulated of all human proteins, and ODC1 is a drug target in oncology and infectious disease ${ }^{17,18}$. SAT1 transcription is also highly-regulated, and its acetylation of polyamines promotes their cellular export ${ }^{18}$. Interestingly, numerous large genomic studies link polymorphisms in SAT1 with suicidal behavior ${ }^{19}$. In neurons, polyamines play important roles in synaptic transmission by conferring inward rectification to certain potassium channels, AMPA receptors and nACh receptors ${ }^{20-22}$. Polyamines also participate in the pathogenesis of neurodegenerative disorders ${ }^{17}$ and the excitotoxicity associated with cerebral ischemia ${ }^{23}$.

We now find that polyamines also control assembly of neuronal $\alpha 4 \beta 2$ and $\alpha 7$ receptors. By contrast, polyamines do not modulate assembly of a6 $\beta 4 \mathrm{nAChRs}$, AMPA receptors or any other ion channel tested. Whereas polyamines classically regulate channel gating by occluding the ion pore, polyamine regulation of $\mathrm{nAChR}$ assembly instead relies on negatively charged residues within the $\alpha 4$ or $\alpha 7$ cytosolic loop. Neuropharmacology studies using wild-type and $\mathrm{NACHO}$ knockout mice show that lowering polyamine levels selectively upregulates cerebrocortical $\alpha 4 \beta 2$ and $\alpha 7$ levels and enhances the neuroprotective properties of nicotine. These studies identify an unexpected role for polyamines in controlling ion channel biogenesis and suggest new strategies in neuropharmacology.

\section{Results}

Genome-wide screening identifies SAT1 as an enhancer of nAChR. To identify novel regulators of $\alpha 4 \beta 2$ receptors, we co- transfected human embryonic kidney 293T cells (HEK293T) with plasmids encoding $\alpha 4$ and $\beta 2$ subunits along with individual constructs from a 5943-cDNA clone library from the Broad Institute $^{24}$. Transfected cells were stimulated with nicotine $(100$ $\mu \mathrm{M})$ and intracellular $\mathrm{Ca}^{2+}$ was quantified with a fluorescence imaging plate reader (FLIPR) (Fig. 1a). As previously shown ${ }^{11}$, a $4 \beta 2$ alone produced a small nicotine-evoked $\mathrm{Ca}^{2+}$ signal, and co-transfection with NACHO significantly enhanced this (Fig. 1a). High throughput screening identified a single clone that profoundly augmented the nicotine-induced $\mathrm{Ca}^{2+}$ response-to levels much higher than NACHO; this clone encoded spermidine/ spermine N1-acetyltransferase (SAT1) (Fig. 1a).

We evaluated the effect of SAT1 on other nAChRs and other Cys-loop receptors both by FLIPR and electrophysiology. Consistent with our screening results, SAT1 dramatically increased ACh-evoked currents from a $4 \beta 2$ (Fig. 1c, d). SAT1 also synergized with NACHO to further enhance the $\alpha 4 \beta 2$ mediated $\mathrm{Ca}^{2+}$ influx (Fig. 1b, d), suggesting that SAT1 and NACHO employ different mechanisms. Whereas SAT1 alone did not rescue homomeric $\alpha 7$ function, SAT1 powerfully synergized with NACHO to increase a7 mediated currents (Fig. 1b-d). In contrast, SAT1 had no significant effect on $a 6 \beta 4$ or 5 -HT3A receptor function (Fig. 1b-d).

SAT1, a small cytosolic protein, is the rate-limiting enzyme for polyamine catabolism (Supplementary Fig. 1). Together with polyamine oxidase, SAT1 acetylates higher-order polyamines converting them to inactive forms that are transported out of cells $^{18}$. By lowering polyamine levels, SAT1 effects on nAChRs could reflect disinhibition, as polyamines can negatively affect nAChR gating 22 . This seemed unlikely for two reasons, First, a6containing $\mathrm{nAChRs}$ are more sensitive to polyamine inhibition of gating than are $\alpha 7^{25}$ whereas we find the opposite sensitivity to SAT1 in our functional assays (Fig. 1b-d). Second, polyamines do not block nAChRs at the hyperpolarized membrane potentials we used for patch clamp studies ${ }^{22}$. As an alternative mechanism, we asked whether SAT1 increases nAChR surface expression. To assess this, we utilized extracellular HA-tagged subunits that allow detection of surface receptors without disrupting channel function ${ }^{11}$. Strikingly, SAT1 boosted surface levels of both $\alpha 4 \beta 2$ and $\alpha 7$ (Fig. 2a, b). SAT1 also augmented surface trafficking atop the effects of the $\alpha 7$ protein chaperones Ric-3, Bcl- $\mathrm{X}_{\mathrm{L}}$, and Mcl-1, as well as the a7 chemical chaperone/orthosteric antagonist, methyllycaconitine (MLA) (Supplementary Fig. 2a, b) implying that receptor upregulation by SAT1 involves a mechanism distinct from any previously described.

SAT1 promotes assembly of $\mathbf{n A C h R s}$ by catalyzing polyamines. To determine whether effects on nAChRs involve the catalytic activity of SAT1, we constructed a Tyr140Phe mutant that abolishes SAT1 enzyme activity ${ }^{26}$. This mutant SAT1 (mutSAT1) did not change surface expression of $\alpha 4 \beta 2$ or $\alpha 7$ receptors in the presence or absence of NACHO (Fig. 2a, b). Ornithine decarboxylase 1 (ODC1) is the rate-limiting enzyme for polyamine synthesis (Supplementary Fig. 1), and difluoromethylornithine (DFMO) is an ODC1 active site inhibitor ${ }^{27}$ that depletes cellular polyamines ${ }^{18}$. Like SAT1 co-transfection, DFMO pretreatment augmented surface expression of $\alpha 4 \beta 2$ and synergized with $\mathrm{NACHO}$ to further enhance $\alpha 4 \beta 2$ and $\alpha 7$ surface receptors (Fig. 2a, b). Pursuing the opposite tact, we found that co-transfection with the polyamine biosynthetic enzymes $\mathrm{ODC1}$ and adenosylmethionine decarboxylase 1 (AMD1) diminished nAChR surface staining (Supplementary Fig. 3a, b). Neither catabolic (SAT1 co-transfection or DFMO pretreatment) nor anabolic (ODC1 and AMD1 co-transfection) polyamine manipulations affected surface expression of the 5HT3A receptor (Fig. 2a, b; Supplementary Fig. 3a, b). 


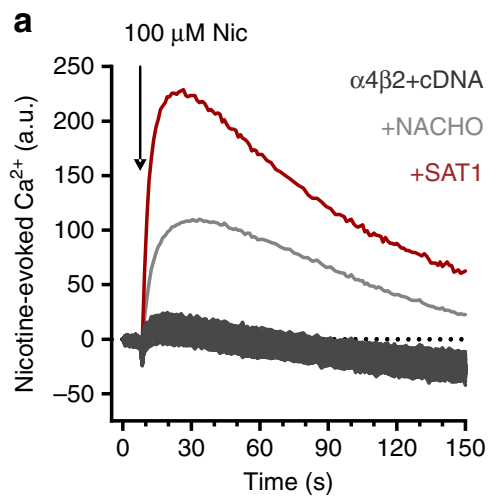

C
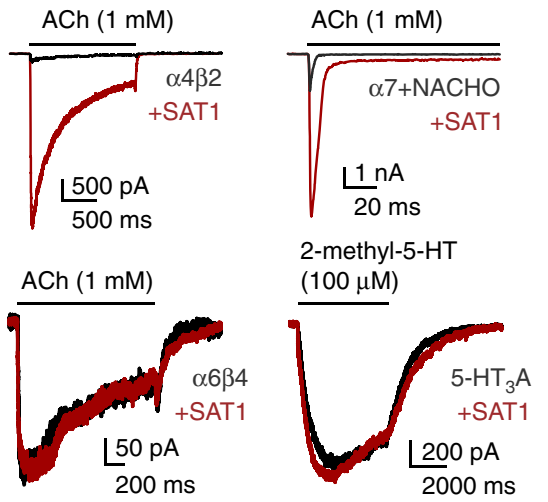

b

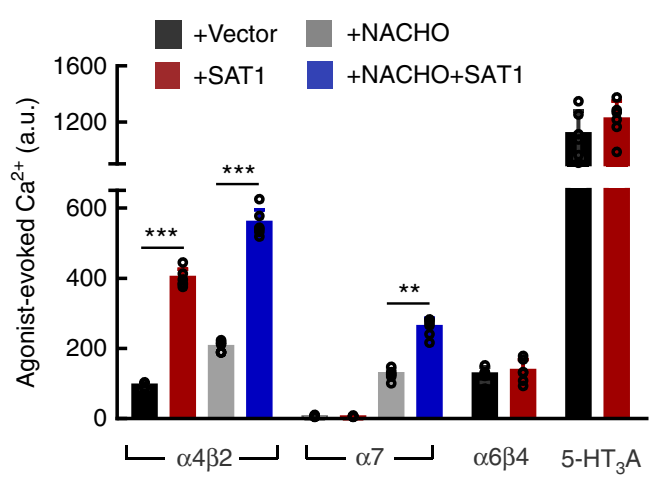

d

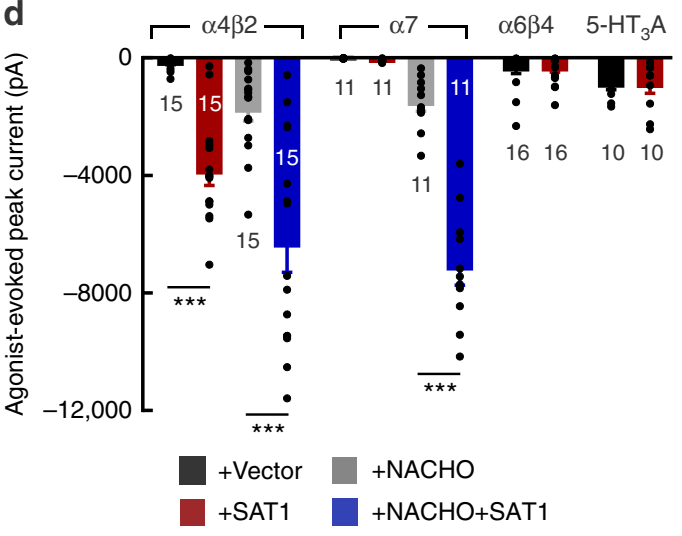

Fig. 1 High throughput cDNA screening for enhancers of $\mathbf{\alpha 4 \beta 2}$ function identifies SAT1. a HEK293T cells in 384-well plates were co-transfected with $\alpha 4$-expressing and $\beta 2$-expressing plasmids along with an individual cDNA (black traces) from a human ORF collection (Broad Institute). Cells were stimulated with $100 \mu \mathrm{M}$ nicotine (Nic). The highest response occurred in the well containing SAT1 (red trace) and was twice the $\alpha 4 \beta 2+\mathrm{NACHO}$ response (gray trace), which served as positive control. b Quantification (mean $\pm \mathrm{SD}$ ) of maximum $\mathrm{Ca}^{2+}$ signal upon agonist stimulation from HEK293T cells transfected as indicated $(n=6)$. Co-transfection of SAT1 significantly enhances $\mathrm{Ca}^{2+}$ signal in $\alpha 4 \beta 2\left(p<1 \mathrm{e}^{-4}\right), \alpha 4 \beta 2+\mathrm{NACHO}\left(p<1 \mathrm{e}^{-4}\right)$ and $\alpha 7+\mathrm{NACHO}(p=0.002)$ cells. For all $\alpha 6 \beta 4$ conditions, cells were co-transfected with plasmids encoding accessories BARP and SULT2B13.

c Representative whole-cell current responses elicited from HEK cells co-transfected with GFP and cDNAs as indicated. $\mathbf{d}$ Summary graphs of agonistevoked peak currents (mean \pm SEM) from HEK293T cells transfected with indicated cDNA combinations. Similar to maximum Ca ${ }^{2+}$ signal, co-transfection of SAT1 boosts evoked currents mediated by $\alpha 4 \beta 2\left(p<1 \mathrm{e}^{-4}\right), \alpha 4 \beta 2+\mathrm{NACHO}\left(p<1 \mathrm{e}^{-4}\right), \alpha 7+\mathrm{NACHO}\left(p<1 \mathrm{e}^{-4}\right)$ but not $\alpha 6 \beta 4(p=0.98)$ or $5-\mathrm{HT} \mathrm{T}_{3} \mathrm{~A}(p=$ 0.73). Numbers indicate number of transfected cells that were analyzed and were pooled from three independent cultures. ${ }^{\star \star} p<0.01,{ }^{\star \star \star} p<0.001$, Oneway ANOVA between the groups for $\alpha 4 \beta 2$ and $\alpha 7$. Mann-Whitney $U$ test versus control for $\alpha 6 \beta 4$ and $5-H T_{3} A$. Source data for panel $\mathbf{b}$ and $\mathbf{d}$ are provided as a Source Data file.

We asked next whether polyamines influence nAChR assembly, which can be probed with orthosteric ligands, such as $\left[{ }^{3} \mathrm{H}\right]$ epibatidine, that only bind at the interface between folded subunits $^{28}$. Remarkably, either SAT1 or DFMO enhanced $\left[{ }^{3} \mathrm{H}\right]$ epibatidine binding to $\alpha 4 \beta 2$ or $\alpha 7$ receptors (Fig. 2c). Furthermore, ODC1 and AMD1 reduced ligand binding to these receptors (Supplementary Fig. 3c).

N1,N11-bis-(ethyl)-norspermine (BenSpm) is a stable polyamine analog and SAT1 inhibitor ${ }^{26,29}$, and treatment of cells with $10 \mu \mathrm{M}$ BenSpm specifically reversed the effects of SAT1 on nAChR surface expression (Fig. 2d). By contrast, incubating cells with spermine, which does not penetrate cells and is rapidly degraded by SAT1, did not affect nAChR surface expression (Fig. 2d). Taken together, we find that polyamines, independent of their established role in ion channel gating, enhance nAChR function by promoting surface expression and augmenting receptor assembly.

Polyamines regulate $\mathrm{nAChRs}$ assembly via their cytosolic loop. Certain neuronal nAChRs display blunted ion flow at depolarized potentials. This inward rectification is mediated by polyamine binding to pore-lining glutamate residues in the nAChR transmembrane domain 2 (TM2) corresponding to Glu247 in $\alpha 4^{22,30}$. It was previously shown that mutating this acidic residue to alanine $\left(\alpha 4_{\mathrm{E} 247 \mathrm{~A}}\right)$ relieves polyamine block of $\alpha 4 \beta 2$ channels in Xenopus laevis oocytes ${ }^{22}$. Loss of negative charge in the $\alpha 4_{\mathrm{E} 247 \mathrm{~A}}$ also reduces calcium permeability through the mutant receptor. Accordingly, we found that a E247A a 4 mutant (Fig. 3a) cotransfected with $\beta 2$ evinced minimal nicotine-evoked $\mathrm{Ca}^{2+}$ influx in HEK293T cells (Fig. 3b), and this was unaffected by preincubation with DFMO or co-transfection with SAT1. By contrast, DFMO or SAT1 enhanced surface expression of $\alpha 4_{\mathrm{E} 247 \mathrm{~A}} / \beta 2$ similar to wildtype $\alpha 4 \beta 2$ (Fig. 3c, d). These data establish distinct mechanisms for polyamine regulation of $\mathrm{nAChR}$ gating and trafficking.

We next mutated Trp156 (Fig. 3e) in the a4 ligand-binding domain $^{30}$. As expected, when co-transfected with $\beta 2$, this $\alpha 4_{\mathrm{W} 156 \mathrm{~A}}$ mutant was functionally inactive and did not bind to $\left[{ }^{3} \mathrm{H}\right]$ epibatidine (Fig. 3f, g). By contrast, this mutant showed typical surface staining enhancement upon co-transfection with SAT1 cDNA (Fig. 3h, i) indicating that polyamine regulation is independent of agonist binding.

To identify nAChR regions responsible for regulation, we generated chimeras of $\alpha 4$ with $a 6$, as surface expression of the latter is not regulated by polyamines (Fig. 4a). We co-transfected 
a

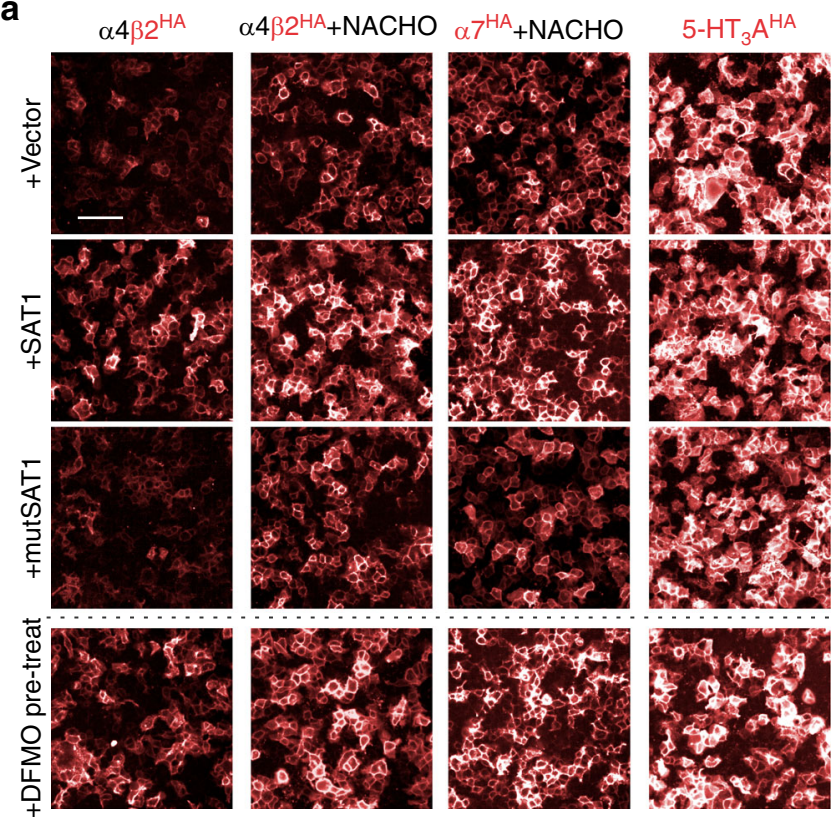

b

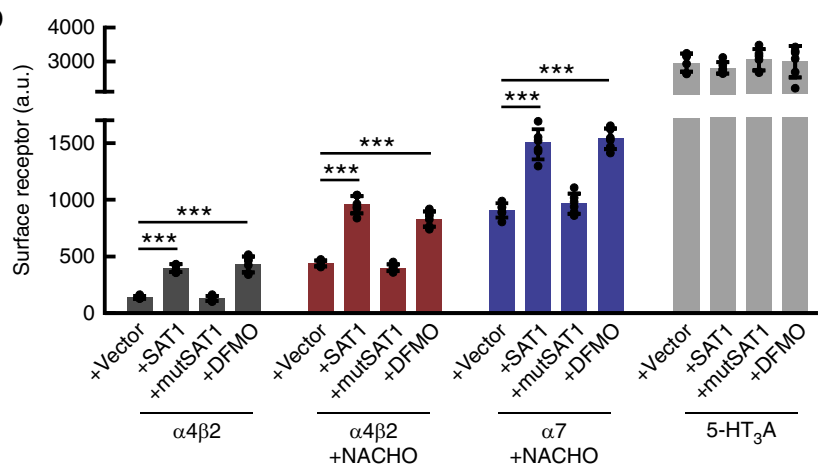

C

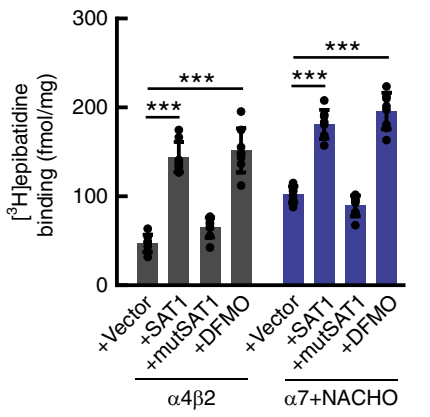

d

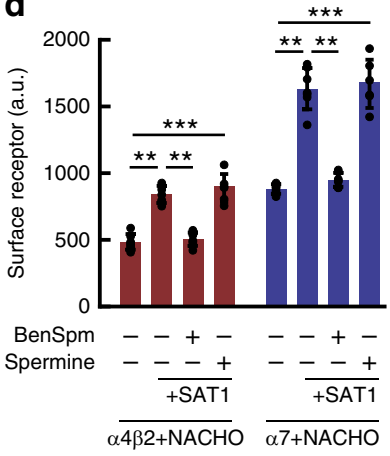

these $\alpha 4 / \alpha 6$ chimeras with $\beta 4$ and quantified both receptor surface expression and nicotine-evoked $\mathrm{Ca}^{2+}$ signaling (Fig. 4). SAT1 co-transfection enhanced a chimera containing the a6 Nterminal and $\alpha 4 \mathrm{C}$-terminal region but did not affect the converse chimera (Fig. 4a-c), which implies that polyamine regulation involves the channel or the large cytosolic loop, which occurs between TM3 and TM4. We next constructed a pair of chimeras that swapped only this cytosolic loop. Quantification of receptor surface expression and function showed that the a 4 TM3-TM4 cytosolic loop is both necessary and sufficient for SAT1dependent regulation of these nAChRs (Supplementary Fig. 4). Similarly, exchanging the TM3-TM4 loop of homomeric a7 receptor with that of a6 (Supplementary Fig. 4d) abolished SAT1mediated upregulation of alpha-bungarotoxin ( $\alpha$-Bgt) binding
Fig. 2 By catalyzing polyamines, SAT1 promotes surface expression and assembly of nAChRs. a HEK293T cells were co-transfected with cDNAs encoding HA-tagged receptors and other plasmids as indicated. Some cells were pre-treated for $24 \mathrm{~h}$ with $1 \mathrm{mM}$ DFMO. Immunofluorescent labeling of the extracellular HA-tag in unpermeabilized cells enabled visualization (red) of surface receptors. Scale bar $=50 \mu \mathrm{m}$. b Summary graph quantifies surface HA-labeling $(n=6)$. Co-transfection with wildtype SAT1, not its mutant version, promotes surface expression of $\alpha 4 \beta 2\left(p<1 e^{-4}\right)$, $\alpha 4 \beta 2+\mathrm{NACHO}\left(p<1 \mathrm{e}^{-4}\right)$ and $\alpha 7+\mathrm{NACHO}\left(p<1 \mathrm{e}^{-4}\right)$ but not $5-\mathrm{HT}_{3} \mathrm{~A}$ $(p=0.84)$. Pre-treating cells with DFMO show comparable results. c Quantification of $\left[{ }^{3} \mathrm{H}\right]$ epibatidine binding to HEK293T cell membranes transfected and pre-treated with DFMO where indicated $(n=8)$. Similar to surface HA-labeling, SAT1 co-transfection and DFMO preincubation increase radioligand binding to $\alpha 4 \beta 2\left(p<1 \mathrm{e}^{-4}\right)$ and to $\alpha 7+\mathrm{NACHO}$ $\left(p<1 \mathrm{e}^{-4}\right)$. d Quantification of surface $\alpha 4 \beta 2-\mathrm{HA}$ or $\alpha 7-\mathrm{HA}$ in HEK293T cells transfected with SAT1 and pretreated with $\operatorname{BenSpm}(n=7)$ or spermine $(n=6)$ as indicted. Only BenSpm occludes SAT1 mediated increase of surface $\alpha 4 \beta 2\left(p=1 \mathrm{e}^{-3}\right)$ or $\alpha 7\left(p=1 \mathrm{e}^{-3}\right)$. Data in $\mathbf{b}-\mathbf{d}$ are presented as mean \pm SD. ${ }^{\star \star} p<0.01,{ }^{\star \star \star} p<0.001$, One-way ANOVA between the groups. Source data for panel $\mathbf{b}-\mathbf{d}$ are provided as a Source Data file.

sites on $\alpha 7$ (Supplementary Fig. 4e, f), which demonstrates that the intracellular loop determines polyamine-regulation of both $\alpha 4$ and $\alpha 7 \mathrm{nAChR}$ assembly.

Previous studies noted that, within the T3-TM4 loop, a subdomain proximal to TM4 contains conserved positively and negatively charged residues ${ }^{31}$. Interestingly, we observed certain negatively charged residues (Glu and Asp) in this subdomain that are conserved between $\alpha 7$ and $\alpha 4$ but diverge in $a 6$ to uncharged Asn (Supplementary Fig. 5a, b) ${ }^{31}$. Mutating those Glu and Asp to Ala in $\alpha 7\left(\mathrm{E}_{438} \mathrm{~A}\right.$ or $\left.\mathrm{D}_{451} \mathrm{~A}\right)$ and $\alpha 4\left(\mathrm{E}_{569} \mathrm{~A}\right.$ or $\left.\mathrm{D}_{582} \mathrm{~A}\right)$ blocked SAT1-mediated upregulation of $\alpha 7$ assembly (Supplementary Fig. $5 c, d$ ) and $\alpha 4 \beta 2$ surface expression (Supplementary Fig. 5 e, f). By contrast, these mutations did not blunt effects of Ric-3 on $\alpha 7$ or NACHO on $\alpha 4 \beta 2$. Replacing the corresponding Asn residues $\left(\mathrm{N}_{434}\right.$ or $\left.\mathrm{N}_{447}\right)$ to Glu within the a6 cytosolic loop conferred moderate but significant SAT1 and DFMO sensitivity to $a 6 \beta 4$ receptors (Supplementary Fig. $5 \mathrm{~g}, \mathrm{~h}$ ). These experiments identify negatively charged residues within the TM3-TM4 cytosolic loop that can mediate polyamine regulation of $\mathrm{nAChR}$ assembly and surface expression. Future studies are needed to fully elucidate these mechanisms.

Polyamines regulate $\mathrm{nAChR}$ gating and assembly independently. To further distinguish mechanisms for polyamine control of nAChR assembly and gating, we compared effects of the membrane-permeant polyamine analog BenSpm with philanthotoxin-343 (PhTx-343), which cannot enter cells and engages the channel pore via a long polyamine tail ${ }^{25,32}$. Neither BenSpm nor PhTx-343 preincubation changed basal surface levels of $\alpha 4 \beta 2$. Whereas BenSpm abrogated SAT1-mediated enhancement of surface $\alpha 4 \beta 2$, PhTx-343 did not (Fig. 5a, b). By contrast, both BenSpm and PhTx-343 preincubation abolished nicotineevoked $\mathrm{Ca}^{2+}$ with or without SAT1 co-transfection (Fig. 5c). These data demonstrate that only cell-permeant polyamines can control of nAChR surface trafficking.

To more completely elucidate these mechanisms, we compared effects of BenSpm and PhTx-343 on a4-containing and a6containing receptors, as SAT1 regulates trafficking of $\alpha 4 \beta 4$ but not $a 6 \beta 4$ (Fig. $4 \mathrm{~b}$ ). As expected, pre-treatment with BenSpm, but not PhTx-343, reversed SAT1-mediated enhancement of a4 $\beta 4$ surface expression and neither had effect on a6 $\beta 4$ surface expression (Fig. 5d, e). By contrast, both BenSpm and PhTx-343 
a

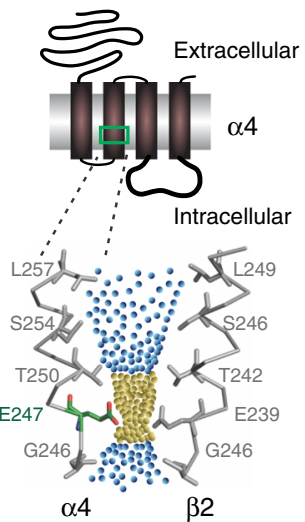

d
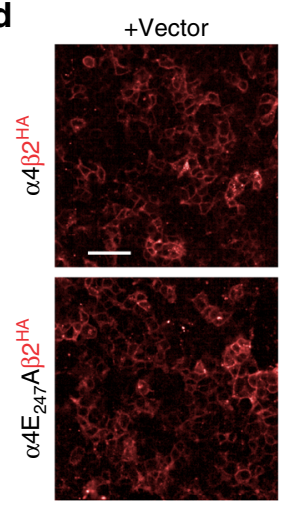

e

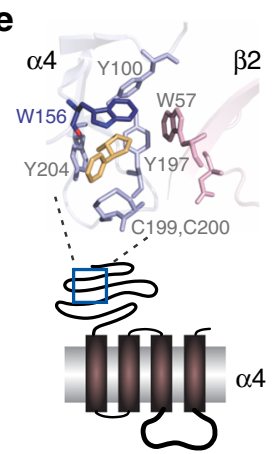

b

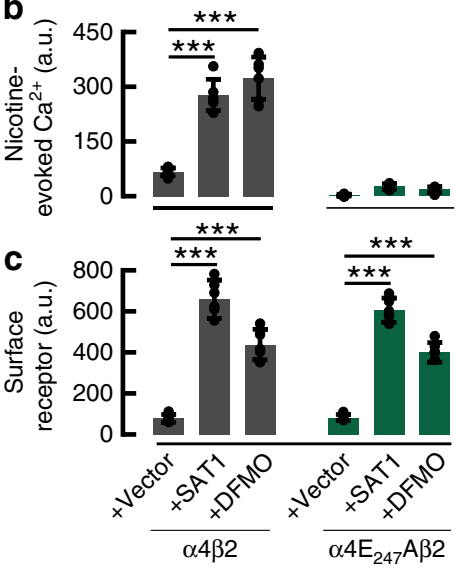

Fig. 3 Polyamine regulation of $\alpha 4 \beta 2$ assembly is mechanistically distinct from channel gating or agonist binding. a Cartoon depicting $\alpha 4 \mathrm{nAChR}$ subunit. Enlarged view (bottom) highlights Glu247 in $\alpha 4$ TM2 critical for polyamine regulation of gating and $\mathrm{Ca}^{2+}$-permeability. Yellow spheres represent pore diameter $>2.8 \AA$, blue spheres $>5.6 \AA$. (PDB: $5 \mathrm{KXI}$ ) b Quantification shows wild-type $\alpha 4 \beta 2$-mediated peak nicotine-evoked $\mathrm{Ca}^{2+}$ is enhanced in cells co-transfected with SAT1 $\left(p<1 e^{-4}\right)$ and pretreated with DFMO $\left(p<1 \mathrm{e}^{-4}\right) . \alpha 4 \mathrm{E}_{247} \mathrm{~A} \beta 2$ transfected cells have reduced nicotine-evoked $\mathrm{Ca}^{2}+(p=0.01)$, which is not changed with SAT1 or DFMO $(n=6)$. c Summary graph $(n=6)$ and $\mathbf{d}$. representative images of fluorescent anti-HA labeling of non-permeabilized HEK293T cells transfected as indicated and pretreated with DFMO where noted (Scale bar $=50 \mu \mathrm{m})$. Quantifications are displayed as mean \pm SD. ${ }^{\star \star \star} p<0.001$, One-way ANOVA between the groups. e Cartoon depicting $\alpha 4 \mathrm{nAChR}$ subunit. Enlarged view (top) highlights Trp156 in $\alpha 4$ that forms a cation- $\pi$ interaction with nicotine (yellow). f Nicotine-evoked $\mathrm{Ca}^{2+}$ from wild-type $\alpha 4 \beta 2$ (black trace) or mutant $\alpha 4 \mathrm{~W}_{156} \mathrm{~A} \beta 2$ (blue trace) (PDB: $5 \mathrm{KXI}$ ). g Binding of $\left[{ }^{3} \mathrm{H}\right]$ epibatidine $(10 \mathrm{nM})$ to HEK293T cell membranes is significantly reduced $\left(p<1 e^{-5}\right)$ in mutant $\alpha 4 \mathrm{~W}_{156} \mathrm{~A} \beta 2$ co-transfected group compared with wild-type $\alpha 4 \beta 2(n=8)$. $\mathbf{h}$ Fluorescent anti-HA labeling of non-permeabilized HEK293T cells transfected as indicated. Scale bar $=50$ $\mu \mathrm{m}$. i Quantification of surface labeling from $\mathbf{h}(n=6)$. SAT1 enhances surface labeling of both $\alpha 4 \beta 2(p=0.002)$ and $\alpha 4 W_{156} \mathrm{~A} \beta 2(p=0.002)$ receptors. NACHO cDNA was included for all receptor transfections in $\mathbf{f - i}$. Quantifications are means \pm SD. ${ }^{\star \star} p<0.01,{ }^{\star \star \star} p<0.001$, Mann-Whitney $U$ test versus control was used for data shown in panel $\mathbf{g}$, $\mathbf{i}$. Source data for panels $\mathbf{b}, \mathbf{c}, \mathbf{g}$ and $\mathbf{i}$ are provided as a Source Data file.

reverse SAT1-mediated enhancement of receptor surface expression, and PhTx-343 did not alter surface expression for any chimera (Fig. 5e and Supplementary Fig. 6d, e). By contrast, acute application of either BenSpm or PhTx-343 blocked nicotine-evoked $\mathrm{Ca}^{2+}$-signaling from all receptor chimeras in a concentrationdependent manner (Fig. 5f, Supplementary Fig. 6a-c). These molecular biological and pharmacological studies establish distinct mechanisms and protein domains for polyamine control of $\mathrm{nAChR}$ trafficking and gating.

Polyamines regulate assembly of neuronal nAChRs. We next explored whether polyamines upregulate endogenous nAChRs in neurons. Accordingly, we treated cultured rat cortical neurons with DFMO and quantified a7 nAChR surface expression with fluorescent $\alpha$-Bgt. As a positive control, we incubated neurons with $100 \mu \mathrm{M}$ nicotine ${ }^{33}$ and found a significant increase in surface a-Bgt binding sites (Fig. 6a, b). Similarly, treating neurons with DFMO robustly increased surface $\alpha$-Bgt binding (Fig. 6a, b). By contrast, neither DFMO nor nicotine altered surface expression of the AMPA-type glutamate receptor subunit GluA1 (Fig. 6a, b). Preincubating neurons with DFMO also increased the nicotineevoked $\mathrm{Ca}^{2+}$ signal (Fig. 6c), an effect that was comparable to the enhancement seen following nicotine pretreatment. These nicotine-evoked $\mathrm{Ca}^{2+}$ responses reflect $\alpha 7$ activity, as they require the a7-specific positive allosteric modulator (PAM) PNU$12059615^{34}$ and were abolished by the $\alpha 7$-specific inhibitor $\alpha$ Bgt (Fig. 6c).

$\left[{ }^{3} \mathrm{H}\right]$ Epibatidine binding in brain largely reflects $\alpha 4 \beta 2$ receptors and was absent in cerebral cortex of a4 knockout mice ${ }^{35}$. Importantly, incubating cortical neurons with DFMO or transducing them with a lentivirus expressing SAT1 enhanced levels of $\left[{ }^{3} \mathrm{H}\right]$ epibatidine binding (Fig. 6d), indicating an increased $\alpha 4 \beta 2$ receptor assembly. To confirm polyamine regulation of neuronal $\alpha 4 \beta 2$, we transduced cortical neurons

application abolished nicotine-evoked $\mathrm{Ca}^{2+}$ signaling from either a4 $\beta 4$ or $\alpha 6 \beta 4$ (Fig. 5f).

We next evaluated effects of BenSpm and PhTx-343 on the a6/ a4 chimeric constructs, which swap the extracellular N-terminal or TM3-TM4 cytosolic loop domains. As predicted, the a4 cytosolic loop was necessary and sufficient for BenSpm pre-treatment to

\section{with $\alpha 4$-expressing and $\beta 2$-expressing lentiviruses. Levels of $\left[{ }^{3} \mathrm{H}\right]$}




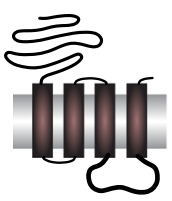

$\alpha 4$

b
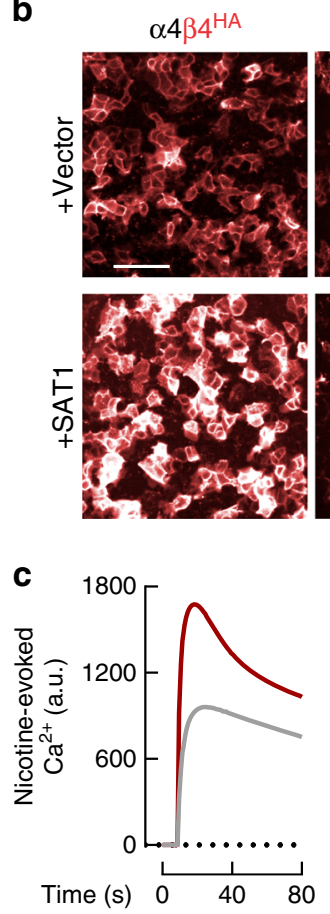
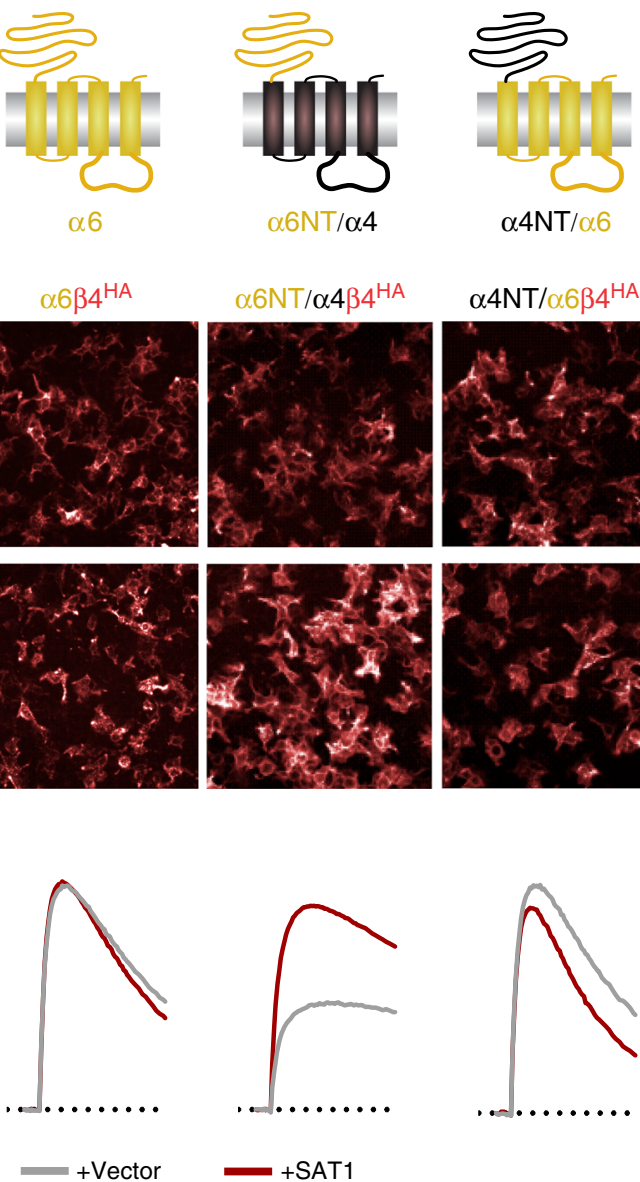

$\alpha 4 \mathrm{NT} / \alpha 6$
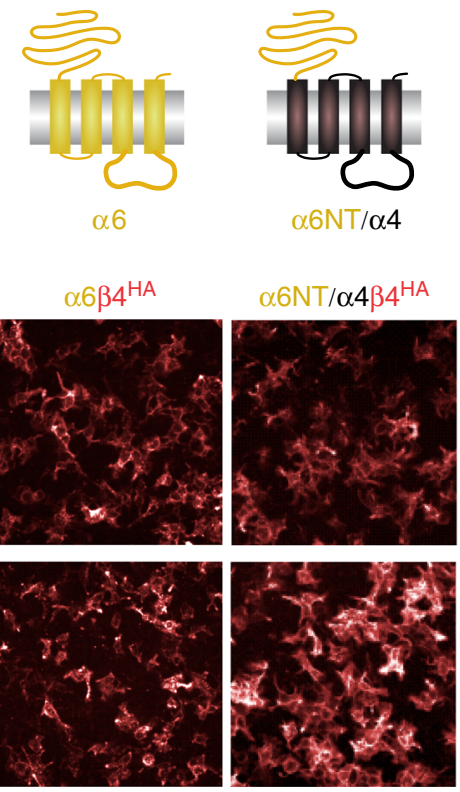

$\alpha 6 \mathrm{NT} / \alpha 4$
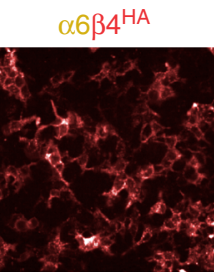

\begin{abstract}
loop determines regul
\end{abstract} As encoding $\alpha 6, \alpha 4, \alpha 4-\alpha 6$ chimeric constructs and extracellular HA-tagged $\beta 4$ with or without SAT1 as indicated. All cDNA combinations contained BARP and SULT2B1. Scale bar $=50 \mu \mathrm{m}$ c. Agonist-evoked Ca ${ }^{2+}$ traces from HEK293T transfected as indicated. The $\alpha 4$ cytosolic loop domain is necessary and sufficient for SAT1-mediated regulation for all chimeras. Note that data in $\mathbf{b}$ and $\mathbf{c}$ are quantified in Supplementary Figs. 4b, c.

epibatidine binding to the transduced neuronal membranes were $\sim 20$ times higher than untransduced neurons, and this was further increased with DFMO pretreatment (Fig. 6d). Importantly, neither DFMO preincubation nor SAT1 transduction altered binding sites for the GABA receptor ligand $\left[{ }^{3} \mathrm{H}\right]$ flunitrazepam (Fig. 6d). Taken together, these data show that polyamines regulate assembly of neuronal nAChR but not AMPA or GABA receptors.

Polyamines modulate nicotine-mediated neuroprotection. Nicotine has well-established neuroprotective properties and can mitigate excitotoxicity in vivo ${ }^{36}$ and in vitro ${ }^{37,38}$. This neuroprotection is mediated both by $\alpha 7^{39}$ and $\alpha 4 \beta 2 n A C h R s^{38,40}$. To assess the functional consequence of polyamine upregulation of receptor assembly, we asked whether this nicotine-mediated neuroprotection could be enhanced by reducing cellular polyamine levels. We induced excitotoxicity by challenging cultured neurons for one hour with glutamate $(30 \mu \mathrm{M})$ and quantified cell survival and cytosolic cytochrome $\mathrm{C}$ (CytC), which is a trigger for apoptosis ${ }^{41,42}$. We also surface-labeled $\alpha 7$ receptors with fluorescent $a$-Bgt. In line with previous reports, glutamate challenge induced excitotoxity and increased cytosolic CytC (Supplementary Fig. 7a-c). Co-application of $100 \mu \mathrm{M}$ nicotine reduced excitotoxicity, but glutamate did not alter surface expression of $\alpha 7$ (Supplementary Fig. 7b, d). On the other hand, neurons pretreated with either DFMO or nicotine showed a three-fold increase in surface $\alpha$-Bgt-binding sites (Supplementary Fig. 7a, d) and a concordant reduction of glutamate-induced CytC release (Fig. 6e; Supplementary Fig. 7c). Nicotine or DFMO preincubation also augmented nicotine-mediated protection from glutamate-mediated excitotoxic cell death (Fig. 6e and Supplementary Fig. 7b).

To more directly link the neuroprotective effects of DFMO with nAChRs, we studied NACHO KO mice, which have dramatically reduced $\mathrm{nAChR}$ function in brain ${ }^{12}$. We found that nicotine blunted glutamate-induced cell death in neurons from wild-type but not NACHO KO mice (Fig. 7a-c). Fitting with results from our rat cortical neuron experiments, we found that pre-treating wild-type mouse neurons with DFMO increased surface $\alpha$-Bgt staining (Fig. 7e) and mitigated glutamate-induced increases in cytosolic CytC (Fig. 7d). By contrast, DFMO pretreatment did not augment $\alpha$-Bgt binding levels in NACHO KO neurons. Accordingly, DFMO preincubation did not confer subsequent nicotine-induced protection from excitotoxic neuronal death in NACHO KO neurons (Fig. 7c). Collectively, these experiments show that polyamines regulate functional assembly of nAChRs, which promotes neuroprotection in wild-type, but not NACHO KO neurons.

\section{Discussion}

This study identifies an unexpected role for polyamines in controlling assembly of neuronal $\alpha 4 \beta 2$ and $\alpha 7$ receptors. Our 
a
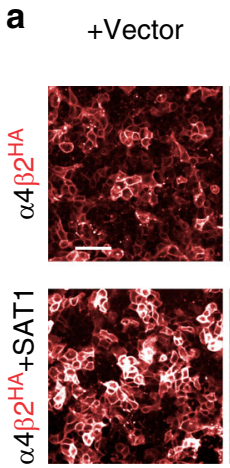

+ BenSpm pre-treat
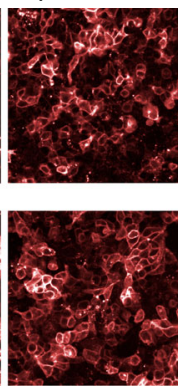

+ PhTx

Pre-treat
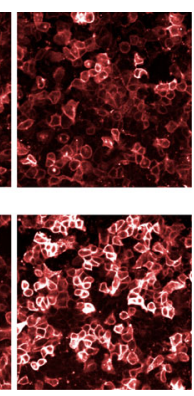

b

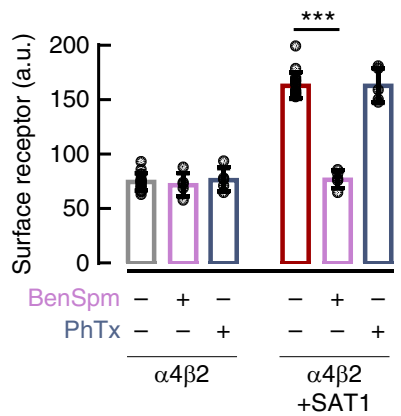

c

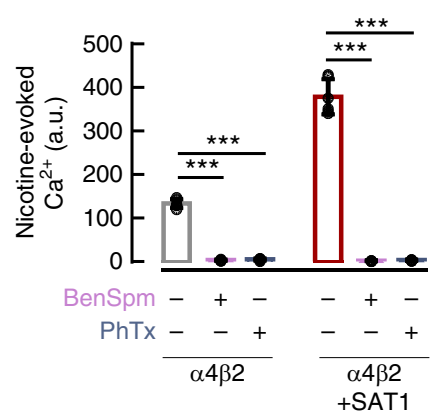

d

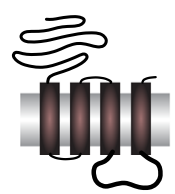

$\alpha 4_{(\beta 4)}$

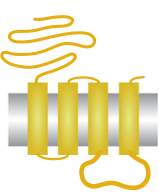

${ }^{\alpha 6}{ }_{(\beta 4)}$

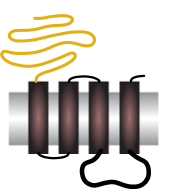

$\alpha 6 \mathrm{NT} / \alpha 4_{(\beta 4)}$

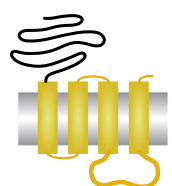

$\alpha 4 \mathrm{NT} / \alpha 6_{(\beta 4)}$

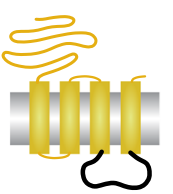

$\alpha 6 / \alpha 4-\operatorname{loop}_{(\beta 4)}$

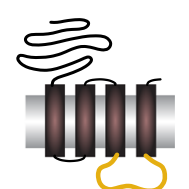

$\alpha 4 / \alpha 6-$ loop $_{(\beta 4)}$

e
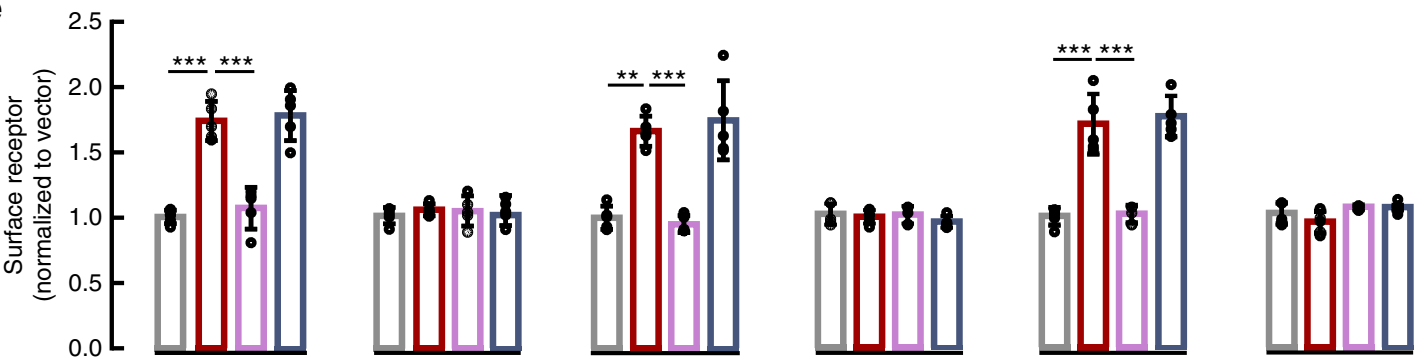

+Vector

+ SAT1

+SAT1+BenSpm

+ SAT1+PhTx
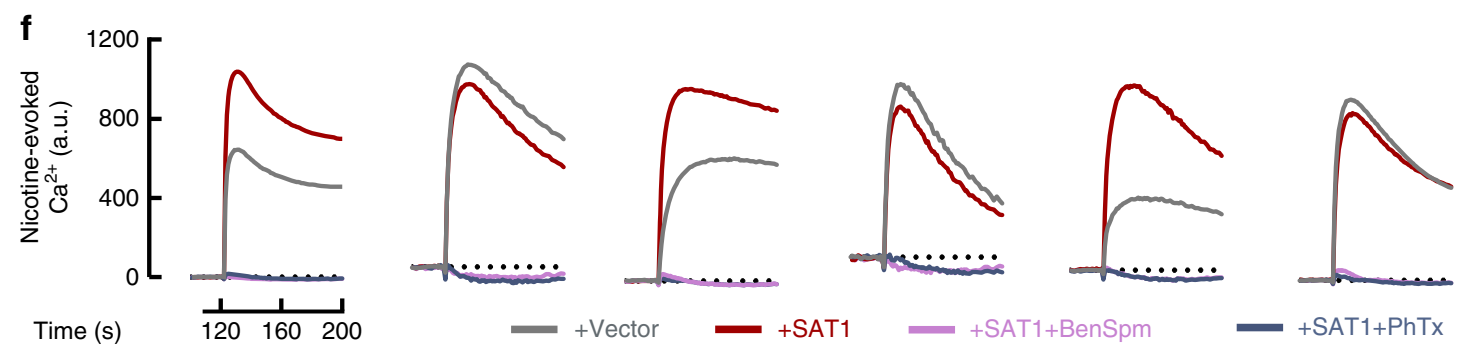

Fig. 5 Polyamine analogs regulate nAChR gating and assembly by distinct mechanisms. a Fluorescent anti-HA labeling of non-permeabilized HEK293T cells transfected with cDNAs encoding extracellular HA-tagged $\beta 2$ and $\alpha 4$ with or without SAT1. Scale bar $=50 \mu \mathrm{m}$. b Quantification of surface staining for $\alpha 4 \beta 2$ receptors with or without SAT1 and BenSpm or PhTx343 pre-treatment $(n=6)$. BenSpm occluded the SAT1-enhanced receptor surface expression $\left(p<1 \mathrm{e}^{-4}\right)$ but PhTx343 had no effect $(p=0.86)$. c Nicotine-evoked Ca ${ }^{2+}$ signal was fully blocked by both BenSpm or PhTx343 $\left(p<1 \mathrm{e}^{-4}\right)(n=$ 6). d Schematics of chimeric constructs of $\alpha 4-\alpha 6$. e Normalized anti-HA surface expression from cells transfected and treated with BenSpm or PhTx343 as indicated $(n=5)$. Only BenSpm occluded SAT1-mediated enhancement of surface receptor expression of $\alpha 4 \beta 4\left(p<1 e^{-4}\right), \alpha 6 N T / \alpha 4 \beta 4\left(p<1 e^{-4}\right)$ and $\alpha 6$ / $\alpha 4$-loop $\beta 4\left(p<1 e^{-4}\right)$. Both SAT1 and BenSpm effects on receptor surface expression required the $\alpha 4$ cytosolic loop. $\mathbf{f}$ Both BenSpm and PhTx343 fully inhibited nicotine-evoked $\mathrm{Ca}^{2+}$ in all receptor combinations. All cDNA combinations included BARP and SULT2B1. Quantifications are displayed as mean \pm SD. ${ }^{\star \star \star} p<0.001$, One-way ANOVA between the groups was used for panels $\mathbf{b}, \mathbf{c}$ and $\mathbf{e}$. Comprehensive dose-response studies are in Supplementary Fig. 5 . Source data for panel $\mathbf{b}, \mathbf{c}$ and $\mathbf{e}$ are provided as a Source Data file.

genome-wide analysis found that SAT1 increases assembly of $\alpha 4 \beta 2$ receptors to a much greater extent than any other protein screened, including the nicotinic receptor chaperone NACHO. Polyamine-regulated assembly is specific for certain nAChRs, is distinct from other nAChR chaperone mechanisms, and requires negatively charged amino acids within the $\alpha 4$ or $\alpha 7$ cytosolic loop. Blocking polyamine synthesis with DFMO upregulates neuronal $\alpha 4 \beta 2$ and $\alpha 7$ surface levels and promotes nicotinemediated neuroprotection, which provides a new angle for drug discovery.
The biogenesis of pentameric nAChRs is a complex and tightly-regulated process ${ }^{43}$. Seminal studies in the 1980s found that nicotine and other orthosteric ligands upregulate brain $\mathrm{nACh}$ protein levels, and this likely participates in nicotine dependence ${ }^{44,45}$. In C. elegans, Ric-3 is required for efficient assembly of worm nAChRs ${ }^{46}$; in mammalian brain, NACHO is required for $\alpha 7^{11}$ and many other nAChRs ${ }^{12}$. Additional proteins synergize with NACHO for assembly of specific mammalian nAChRs. Ric- $3^{14}$ and certain Bcl-2 family proteins ${ }^{15}$ work with $\mathrm{NACHO}$ to promote function of $\alpha 7$, whereas BARP, LAMP5, and 
a

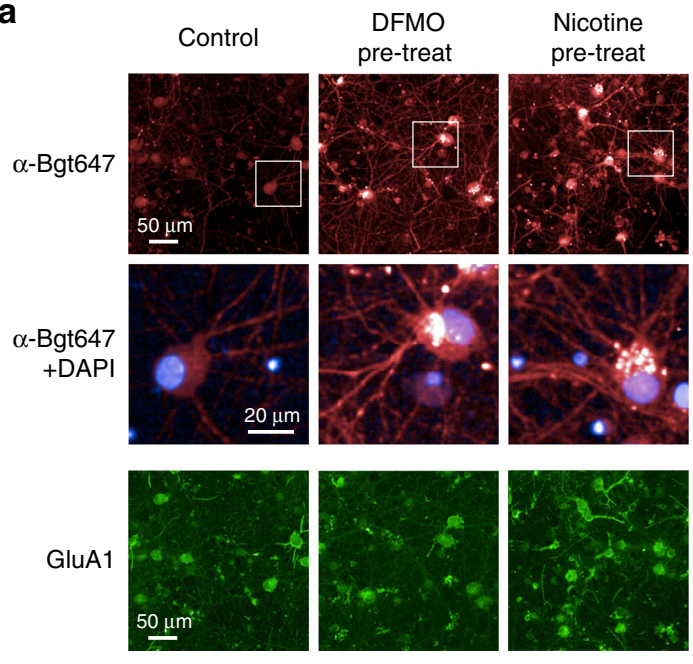

b
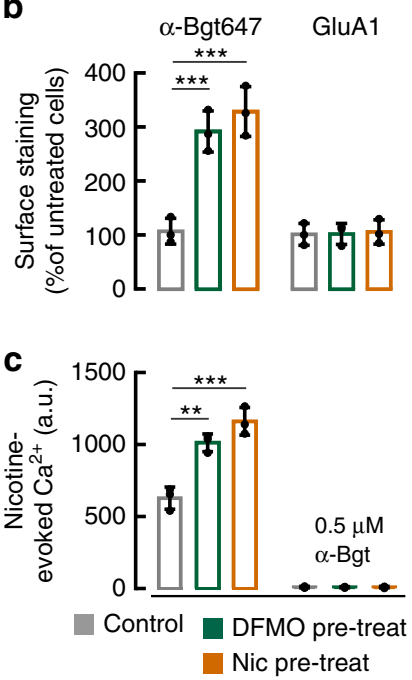
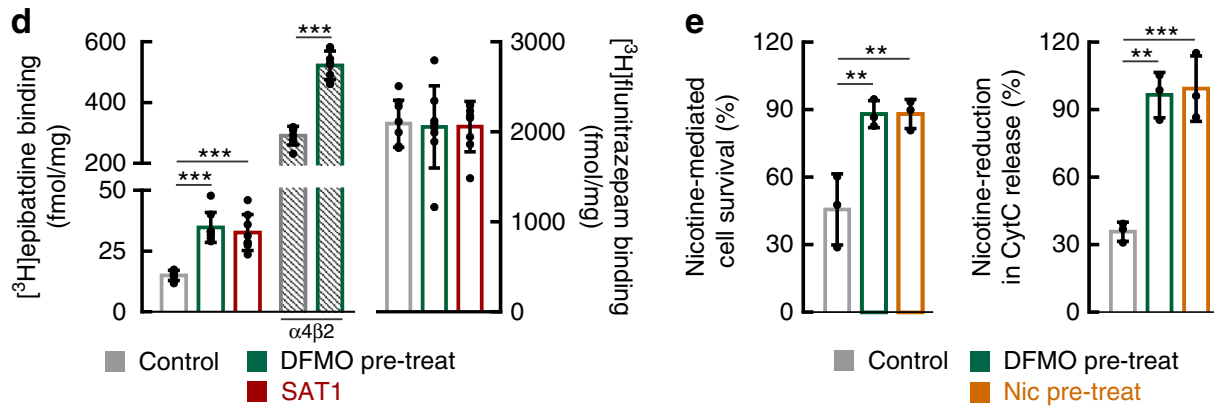

Fig. 6 DFMO enhances both neuronal nAChRs and nicotine-mediated neuroprotection. a Fluorescent labeling of non-permeabilized rat cortical neurons (DIV 20) shows upregulation of endogenous $\alpha$-Bgt674 labeling in neurons pre-treated for six days with DFMO (5 mM) or nicotine (Nic; $100 \mu M)$ as indicated. Surface-labeling for $\alpha 7$ used $\alpha$-Bgt647 (red) and insets (white squares) depict magnifications that include DAPI (blue). Double-labeling with $\alpha$ GluA1 (green) served as control. b Quantification of surface $\alpha$-Bgt647 shows increased staining with both DFMO and Nic $\left(p<1 e^{-4}\right)$, but no change was observed in surface GluA1 staining $(p=0.9)$. c Summary graph showing nicotine $(100 \mu \mathrm{M})+\mathrm{PNU}-12059615-(10 \mu \mathrm{M})$ evoked Ca ${ }^{2+}$ from rat cortical neurons (DIV 13) increases when pre-treated for six days with DFMO $(p=0.002)$ or nicotine $(p=0.0004)$. Responses were blocked by $\alpha$-Bgt $(0.5 \mu M)$. Data shown in B and $\mathrm{C}$ were averaged from 3 independent experiments each containing 6 independent samples. $\mathbf{d}$ Quantification of $\left[{ }^{3} \mathrm{H}\right]$ epibatidine (10 $\mathrm{nM})$ and $\left[{ }^{3} \mathrm{H}\right]$ flunitrazepam $(50 \mathrm{nM})$ binding to membranes from neurons pre-treated with DFMO or transduced with SAT1 show selective increase in $\left[{ }^{3} \mathrm{H}\right]$ epibatidine binding $\left(p<1 \mathrm{e}^{-4}\right)$. One-way ANOVA compared to control. Neurons transduced with lentivirus expressing $\alpha 4$ and $\beta 2$ showed much higher levels of $\left[{ }^{3} \mathrm{H}\right]$ epibatidine binding (hatched bars) $\left(p<1 \mathrm{e}^{-4}\right.$, compared to un-transduced control), and these were further enhanced $\left(p<1 \mathrm{e}^{-4}\right)$ with $\mathrm{DFMO}$ treatment $(n=8)$. e Acute application of nicotine (gray bars) partially reduced glutamate-mediated cell death (left panel) and mobilization of CytC (right panel). Pre-treating neurons for six days with DFMO (green, $5 \mathrm{mM}$ ) enhanced nicotine-mediated cell survival $(p=0.006)$ and decreased CytC mobilization $(p=0.001)$. Nicotine (orange, $100 \mu \mathrm{M}$ ) pre-treatment similarly enhanced nicotine-mediated neuroprotection. Data averaged from 3 independent experiments each containing 6 independent samples. Quantifications are displayed as mean \pm SD. ${ }^{\star \star} p<0.01,{ }^{\star \star \star} p<0.001$, One-way ANOVA between the groups for panels b-e. Source data for panels $\mathbf{b}-\mathbf{e}$ are provided as a Source Data file.

SULT2B1 conspire with NACHO to enhance function of a6containing receptors ${ }^{13}$. Our discovery of SAT1 regulation identifies the polyamine pathway as an additional controlling mechanism for $\alpha 4 \beta 2$ and $\alpha 7$ receptors.

These multiple layers of $\mathrm{nAChR}$ regulation utilize distinct mechanisms. In the case of $\alpha 7, \mathrm{NACHO}$ mediates subunit oligomerization $^{11}$. Subsequent regulation by nicotine, Ric-3, and Bcl-2 proteins synergizes with $\mathrm{NACHO}$ to promote protein folding, receptor surface expression, and channel function ${ }^{14,15}$. Nicotine and other orthosteric ligands promote assembly through a7's ACh binding domain ${ }^{45}$ whereas Bcl-2 proteins $^{15}$ and polyamines engage the receptor cytosolic loop. However, polyamine regulation involves a distinct mechanism, as we find SAT1 augments receptor assembly atop NACHO, nicotinic ligand, Ric-3, or Bcl-2 family proteins.

It is intriguing to ask why nAChRs-but not other receptors in the Cys-loop superfamily including $5-\mathrm{HT} 3$ and $\mathrm{GABA}_{\mathrm{A}}$ receptors -require accessories for functional expression. One possibility is that multiple assembly mechanisms provide regulatory nodes for controlling $\mathrm{nAChR}$ function. NACHO transcription is upregulated by physiological stimuli ${ }^{47}$, and $\mathrm{Bcl}-2$ family protein levels are dynamically-induced during developmental and pathological processes $^{48}$. Furthermore, protein accessories may also determine nAChR cellular localization. The a6-containing nAChRs specifically concentrate at presynaptic terminals of specific monoaminergic neurons, and this may be enabled by the lysosomal protein, LAMP5, which displays a similar restricted distribution ${ }^{49}$.

Polyamines are ubiquitous in biology and play multiple roles in cell growth, survival, and differentiation ${ }^{17}$. In neurons, polyamines control gating of several important ion channels. Cytosolic polyamines confer inward rectification to certain potassium channels, AMPA receptors, and $\mathrm{nAChRs}{ }^{20-22}$. Elegant biophysical studies showed that neuronal depolarization draws cytosolic polyamines into the channel pore, which precludes ion flow $^{20}$. This polyamine site is accessible to extracellular 
a
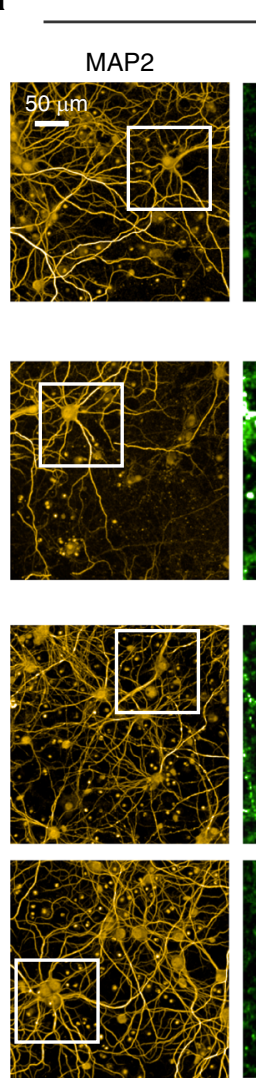

C

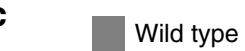

$\mathrm{NACHO} \mathrm{KO}$
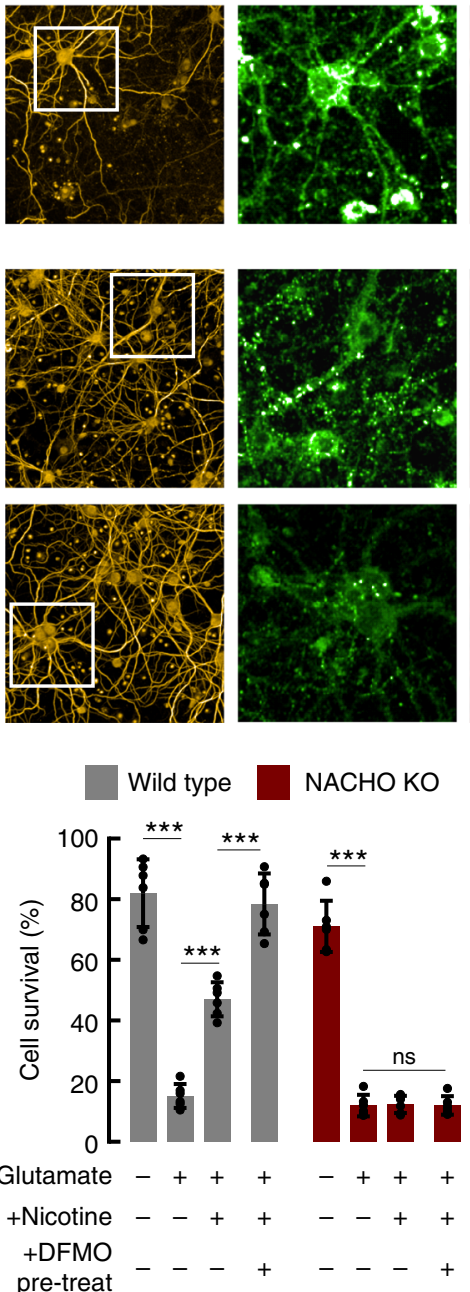

b

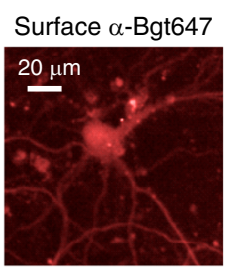

+Glutamate challenge
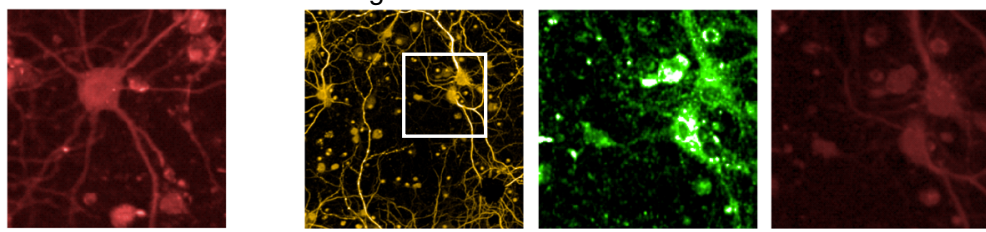

+Glutamate challenge + nicotine
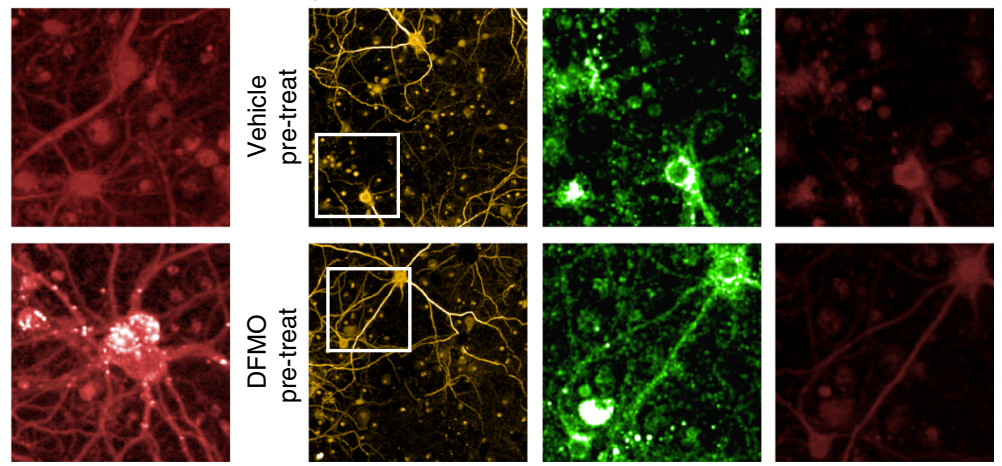

d

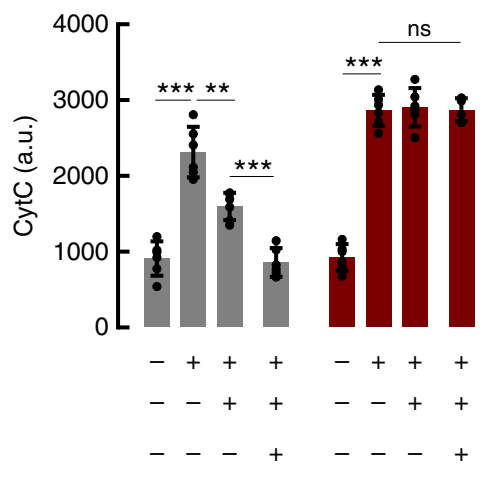

e

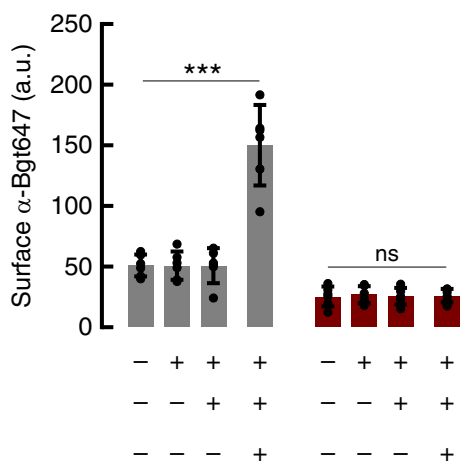

Fig. 7 DFMO promotes nicotine-mediated neuroprotection in a NACHO-dependent fashion. a, b Images of cortical neurons (DIV 20) from wild-type (a) or NACHO KO (b) mice. As indicated, neurons were pretreated with DFMO ( $5 \mathrm{mM}$, 4th row) or and challenged with $30 \mu \mathrm{M}$ glutamate (Glu, 2nd-4th row) in the absence (2nd row) or presence (3rd-4th row) of $100 \mu \mathrm{M}$ nicotine. The cells were stained for MAP2 (left panel) and cytochrome-C (CytC middle panel) and surface $\alpha$-Bgt647 (right panel). White squares indicate regions that are magnified. c-e Graphs quantify neuronal survival (c), CytC (d) and surface $\alpha$-Bgt647 (e) $(n=6)$. Acute nicotine increases cell survival $\left(p<1 \mathrm{e}^{-4}\right)$ and reduces CytC mobilization $(p=0.0002)$ during glutamate toxicity in wild-type neurons, but not in NACHO KO neurons $(p=0.9)$. DFMO pre-treatment further promotes nicotine-mediated cell survival $\left(p<1 \mathrm{e}^{-4}\right)$ and reduces CytC mobilization $(p=0.0002)$ in wildtype neurons. DFMO significantly enhances surface $\alpha$-Bgt647 labeling of wild-type $\left(p<1 e^{-4}\right)$ but not of NACHO KO neurons $(p=0.9) .{ }^{\star \star} p<0.01,{ }^{\star \star \star} p<0.001$, n.s $=$ not significant, one-way ANOVA between the groups. Data displayed as mean \pm SD. Source data for panel c-e are provided as a Source Data file.

philanthotoxins ${ }^{50}$, which have long polyamine tails that can engage the channel.

Our studies decisively establish that regulation of $\alpha 7$ and $\alpha 4 \beta 2$ assembly by polyamines is distinct from their classical role in controlling ion channel gating. First, we find that SAT1 increases $\alpha 4 \beta 2$ and $\alpha 7$ function even when recorded at hyperpolarized potentials that preclude $\mathrm{nAChR}$ gating control by cellular polyamines $^{22}$ (Fig. 1c, d). Second, SAT1 promotes assembly of nonfunctional a $4 \beta 2$ receptors that cannot bind ACh (Fig. 3e-i).
Third, extracellular philanthotoxin acutely blocks $\alpha 4 \beta 2$ receptor function but philanthotoxin does not affect receptor assembly (Fig. 5a-c). Fourth, chronic but not acute application of a cellpermeable polyamine analog, BenSpm, reverses the effects of SAT1 on $\alpha 7$ and $\alpha 4 \beta 2$ receptor assembly and function (Fig. 2d). Interestingly, we find that SAT1 does not augment function of a6-containing nAChRs. Taking advantage of this a-subunit specificity, our a6/a4 chimeras determine that polyamine regulation of channel assembly involves the a 4 cytosolic loop. Again, this is 
distinct from the pore region that determines polyamine control of rectification.

As $\alpha 7$ and $\alpha 4 \beta 2$ are the most abundant nAChRs in human brain and control diverse aspects synaptic signaling and plasticity, polyamine regulation of their assembly has important physiological and pathophysiological implications. Polyamine levels in neurons are dynamically regulated over both short-time and long-time scales. Acutely, synaptic transmission increases synthesis of polyamines, which modulate integrative neuronal properties by reducing AMPA receptor currents ${ }^{51}$ and provide an excitability buffer by negatively regulating $\mathrm{Na}^{+}$channels ${ }^{52}$. Longlasting changes in synaptic transmission associated with pathological processes such as epilepsy dramatically upregulate ODC1 $1^{53}$, which our study predicts would downregulate nAChR assembly. Indeed, a4-containing nAChRs levels are decreased in piriform cortex of kindled mice ${ }^{54}$.

Polyamines and nAChRs share compelling links to neuropsychiatric disorders. Numerous genetic, genomic, and biochemical studies identify alterations in the polyamine pathway in major depressive disorder and suicide ${ }^{55}$. An SNP in the promoter region of SAT1 that reduces expression is associated with suicide in a French-Canadian founder population ${ }^{55}$. Postmortem studies find reduced SAT1 protein and mRNA levels in precentral gyrus and cortical frontal lobe ${ }^{56}$. Also, polyamine levels increase during anxiety episodes, and this polyamine stress response pathway 19 could suppress nAChR assembly. Fitting with this, preclinical and early clinical studies suggest that $\alpha 7$ or $\alpha 4 \beta 2$ agonists can improve depressive behavior in animal models and in depressed patients ${ }^{57}$.

Numerous observations also link polyamine and nAChR alterations with cognitive and neurodegenerative processes. Spermine synthase mutations cause Snyder-Robinson syndrome characterized by mental retardation and juvenile myoclonic epilepsy ${ }^{58}$, and these central symptoms are also found in certain patients with mutations in $a 4 \mathrm{nAChR}^{59}$. Interestingly, both SAT1 overexpression $^{60}$ and nicotine ${ }^{36}$ protect animals from kainateinduced toxicity. Polyamine levels are elevated ${ }^{17}$ and nAChR levels are reduced ${ }^{61}$ in Alzheimer's disease, which is best treated today with cholinesterase inhibitors that augment nAChR activity. Furthermore, $\mathrm{DFMO}^{23}$ and nicotinic agonists ${ }^{40}$ both mitigate neurotoxicity from neuronal ischemia. Our results that blocking ODC1 increases neuronal $\alpha 4 \beta 2$ and $\alpha 7$ and promotes nicotinemediated neuroprotection provide a mechanistic link for these observations. As such, targeting this polyamine/nAChR assembly pathway provides a new neuropharmacological strategy.

\footnotetext{
Methods

Genes and molecular biology and cell culture. The following genes are studied here: (Human forms) CHRNA4 (NM_000744.6), CHRNB2 (NM_000748.2), CHRNA7 (NM_000746.5), CHRNA6 (NM_004198), CHRNB4 (NM_000750), TMEM35A or NACHO (NM_021637.2), Ric-3 (NM_024557.5), Bcl- $\mathrm{X}_{\mathrm{L}}$ (NM_138578.2), Mcl-1 (NM_021960.4), SAT1 (NM_002970.3), ODC1 (NM_002539); (mouse forms) 5HT- ${ }_{3}$ A (NM_013561), AMD1 (NM_009665).

Chimeric constructs used in this study, with residues in the parenthesis are: $\alpha 6 N T / \alpha 4\left(\alpha 6_{1-239} / \alpha 4_{243-628}\right), \alpha 4 N T / \alpha 6\left(\alpha 4_{1-242} / \alpha 6_{240-495}\right), \alpha 6 / \alpha 4 l o o p\left(\alpha 6_{328-465}\right.$ exchanged to $\alpha 4_{331-600}$ ), $\alpha 4 / \alpha 6$ loop ( $\alpha 4_{331-600}$ exchanged to $\alpha 6_{328-465}$ ), $\alpha 7 / \alpha 6$ loop $\left(\alpha 7_{328-457}\right.$ exchanged to $\left.\alpha 6_{339-453}\right)$. In brief, for $\alpha 6 \mathrm{NT} / \alpha 4$ chimera, $\alpha 4_{243-628}$ region and $\alpha 6_{1-239}$ was linearized and amplified with PCR. The primers for $a 6_{1-239}$ contained complementary overhangs immediately upstream and downstream of amplified region. PCR products were ligated using In-Fusion HD Cloning Plus kit (Takara, 683910) in accordance with manufacturer's protocol. All other chimeras were generated following similar strategy and were confirmed by sequencing. Sitedirected mutagenesis was done with two complementary primer reactions (primer details provided in Supplementary Table 1), and all mutations were confirmed by sequencing. The $\alpha 7-\mathrm{HA}, \beta 2-\mathrm{HA}$, and $\beta 4-\mathrm{HA}$ constructs contained a PSGA linker and $\mathrm{HA}$ tag immediately following the $\mathrm{C}$-terminal residue.

HEK293T cells $\left(\right.$ ATCC $^{\circledR}$ CRL-3216 ${ }^{\mathrm{m}}$ ) were cultured in DMEM medium supplemented with $10 \%$ FBS and $1 \mathrm{mM}$ sodium pyruvate. Cells were seeded at 80 $90 \%$ confluence and were transiently transfected using FuGENE ${ }^{\circledR} 6$ transfection reagents (Promega Corporation). All functional and expression assays in
}

HEK293T cells were performed after $48-72 \mathrm{~h}$ incubation at $37^{\circ} \mathrm{C}$ following transfection, unless stated otherwise.

All animal experiments reported here were overseen and approved by an AAALAC accredited institutional review board. Primary cortical neurons were prepared from E18 rat cortex (supplied by BrainBits ${ }^{\circledast}$ ) and E18 mice cortices from wild-type or NACHO knockout mice (TMEM35a $\mathrm{a}^{\mathrm{tml} \text { (KOMP)Vlcg) }}{ }^{11}$ (obtained from the laboratory's vivarium). Cortices were dissociated using $10 \mathrm{U} / \mathrm{mL}$ papain (Worthington) digestion for $10 \mathrm{~min}$, followed by trituration with a $10 \mathrm{~mL}$ glass pipette. Neurons were seeded at 15,000 cells per well (384-well plates) and maintained in NbActiv $4^{\circledast}$ media (BrainBits $^{\circledast}$ ). Immunostaining or FLIPR assays were performed at DIV 20 or DIV 13, respectively, following 6 days incubation in nicotine $(100 \mu \mathrm{M})$ or DFMO $(5 \mathrm{mM})$ as indicated. For radioligand binding assays, neurons were transduced with SAT1 or $\alpha 4$ and $\beta 2$ encoding lentiviruses (DIV 7) or treated with DFMO (DIV 14) and harvested on DIV 20. The lentiviral vectors encoding SAT1, $\alpha 4$ and $\beta 2$ used a PGK promoter for transgene expression. The SAT1-expressing viral particles were packaged by Vigene Biosciences ${ }^{\mathrm{TM}}$, while the $\alpha 4$-expressing and $\beta 2$-expressing viruses were packaged by VectorBuilder.

Broad cDNA library screen. The cDNA library used for $\alpha 4 \beta 2$ screening was from the Broad Institute and contains 5943 cDNA clones. This genome-wide screen used a FLIPR assay on transfected HEK293T cells in 384-well plates. Each well was transfected with $60 \mathrm{ng}$ of total cDNA with the following composition: $\alpha 4: \beta 2$ :single Broad gene (2:4:3). Transfections with NACHO ( $\alpha 4: \beta 2: \mathrm{NACHO}[2: 4: 3])$ served as positive control.

FLIPR assay for agonist-evoked $\mathbf{C a}^{2}+$ influx. High-throughput FLIPR assays were conducted using 384-well BioCoat (Corning) plates. Cells were washed briefly in assay buffer (HyClone ${ }^{\mathrm{TM}}$ HEPES-buffered saline [GE Life Sciences] comprising $149 \mathrm{mM} \mathrm{NaCl}, 4 \mathrm{mM} \mathrm{KCl}, 10 \mathrm{mM}$ HEPES, and $5 \mathrm{mM}$ glucose at $\mathrm{pH} 7.4$ and 300 mOsm osmolality, supplemented with $2 \mathrm{mM} \mathrm{CaCl}_{2}$ and $1 \mathrm{mM} \mathrm{MgCl}_{2}$ ) prior to Calcium5 dye (Molecular Devices) loading for $1 \mathrm{~h}$ at RT. Following removal of excess dye, plates were placed in the FLIPR Tetra (Molecular Devices) chamber, and fluorescent $\mathrm{Ca}^{2+}$ signal was captured using ScreenWorks $4.0^{\text {ix }}$ software (Molecular Devices).

To obtain neuronal $\alpha 7$ mediated FLIPR responses, we used $5 \mu \mathrm{M}$ PNU12059615-a selective drug that attenuates receptor desensitization. Tetrodotoxin or TTX $(500 \mathrm{nM})$ was included in the assay buffer to inhibit spontaneous action potentials.

Immunofluorescent staining and image analysis. HEK293T cells seeded on 384well BioCoat plates (Corning) were incubated with primary antibody against HA tag-Dylight $650^{\circledR}$ (Invitrogen ${ }^{\text {sx }}$ ) in culture media for $1 \mathrm{~h}$ at $37^{\circ} \mathrm{C}$. Cells were fixed with $4 \%$ PFA (in HyClone ${ }^{\mathrm{me}}$ HEPES-buffered saline) for $60 \mathrm{~min}$, and after washing, nuclei were stained with DAPI or NucBlue ${ }^{\circledR}$ reagent (Invitrogen ${ }^{\mathrm{rx}}$ ).

For neurons, cells were fixed with $4 \%$ PFA for $1 \mathrm{~h}$ and then stained with fluorescent $\alpha$-Bgt conjugates $\left(1 \mu \mathrm{g} / \mathrm{mL}\right.$, AlexaFluor 647 , Invitrogen $\left.{ }^{\mathrm{TM}}, \mathrm{B} 35450\right)$ or primary antibodies for $1 \mathrm{~h}$. Then cells were simultaneous permeabilized and blocked in $0.2 \%$ Triton X-100 and $10 \%$ normal goat serum for $30 \mathrm{~min}$. To label intracellular components, neurons were incubated in primary and secondary antibodies sequentially for $1 \mathrm{~h}$ each. Nuclei were stained with DAPI or NucBlue ${ }^{\circledR}$ reagent $\left(\right.$ Invitrogen $^{\text {TM }}$ ) prior to imaging.

Primary antibodies used were: HA (Mouse, 1:500, Invitrogen ${ }^{\text {Ts }}$ 2-2.2.14) conjugated to DyLight 650, GluA1 N-terminal (Mouse, 1:250, Millipore-Sigma RH95), Cytochrome C (Mouse, 1:100, Invitrogen ${ }^{\text {tw }}$ 7H8.2C12), MAP2 (Chicken, 1:1000, Millipore-Sigma AB15452). Secondary antibody used: goat anti-mouse IgG $(\mathrm{H}+\mathrm{L})$ AlexaFluor 488 (Invitrogen $^{\mathrm{TM}}$, A-11001), goat anti-chicken $\operatorname{IgY}(\mathrm{H}+\mathrm{L})$ AlexaFluor 555 (Invitrogen $^{\text {Tx }}, \mathrm{A}-21437$ ) at 1:1000 dilution.

For quantification, images were acquired using Harmony ${ }^{\text {Tx }}$ high-content imaging software on an Opera Phenix ${ }^{\mathrm{TM}}$ screening instrument (PerkinElmer) with a $\times 20$ objective. Data were further analyzed with the Columbus ${ }^{\text {max }}$ data storage and analysis system (PerkinElmer). Viable cells were identified from the DAPI signal (area $>30 \mu \mathrm{m}^{2}$ for HEK293T; area $>10 \mu \mathrm{m}^{2}$ for neurons). Cell perimeter was determined from the nuclear staining, and area of the cytoplasm was calculated based on the cytoplasmic region of interest. Average fluorescence intensity of wells was determined after subtracting the background signal, which was defined as antiHA labeling of untransfected HEK293T cells or as a-Bgt647 labeling not displaced by $10 \mu \mathrm{M}$ epibatidine.

Radioligand binding assays. HEK293T cells or cortical neurons were harvested in $50 \mathrm{mM}$ ice-cold TrisHCl buffer ( $\mathrm{pH}$ 7.4). Cells were homogenized for $30 \mathrm{~s}$ using the T-25 Ultra-Turrax homogenizer (Ika) and total protein concentration of the homogenate was determined using the Pierce ${ }^{\mathrm{Tn}}$ BCA Protein Assay Kit (Thermo Scientific). Cell homogenates were incubated with $10 \mathrm{nM}\left[{ }^{3} \mathrm{H}\right]$ epibatidine (for $\mathrm{nAChR}$ ) or with $30 \mathrm{nM}\left[{ }^{3} \mathrm{H}\right]$ flunitrazepam (for GABA) in 96-well plates for $3 \mathrm{~h}$ at room temperature. Nonspecific binding was determined by co-incubation of the cell samples with $10 \mu \mathrm{M}$ unlabeled epibatidine or $100 \mu \mathrm{M}$ unlabeled flunitrazepam. Assays were terminated by filtration through polyethylenimine-treated 96 -well Unifilter GF/B plates (PerkinElmer). Filter plates were washed with $500 \mathrm{~mL}$ TrisHCL buffer and then desiccated at $65^{\circ} \mathrm{C}$ for $30 \mathrm{~min}$. MicroScint- 0 scintillant 
cocktail $(50 \mu \mathrm{L}$; PerkinElmer) was added to each well and plates read with a TopCount NXT scintillation counter (PerkinElmer)

Electrophysiology. HEK293T cells were seeded (1 million/well) on uncoated sixwell plates and transfected with cDNA combinations (total $2 \mu \mathrm{g} /$ well) using FuGENE ${ }^{\circledR} 6$ transfection reagent (Promega Corporation). eGFP plasmid (10\% of total cDNA) identified transfected cells. After $24 \mathrm{~h}$, cells were dissociated using CellStripper ${ }^{\text {rm }}$ dissociation reagent (Corning) and re-seeded on $12 \mathrm{~mm}$ glass coverslips (40,000/well). Electrophysiological recordings were done $48 \mathrm{~h}$ after transfection using external solution composed of HyClone ${ }^{\mathrm{ms}}$ HEPES-buffered saline (149 mM NaCl, $4 \mathrm{mM} \mathrm{KCl}, 10 \mathrm{mM}$ HEPES, $2 \mathrm{mM} \mathrm{CaCl}_{2}, 1 \mathrm{mM} \mathrm{MgCl}_{2}$ and $5 \mathrm{mM}$ Glucose at $\mathrm{pH} 7.4 ; 300$ mOsm osmolality). Intracellular solution contained (mM): 140 potassium gluconate, 10 HEPES, $4 \mathrm{Mg}$-ATP, $0.4 \mathrm{Na}-\mathrm{GTP}$, and 0.6 EGTA ( $\mathrm{pH}$ 7.3). To study most receptors, fast perfusion of compounds was achieved with the Perfusion Fast-Step system (Warner Instruments). To study a 7 nAChRs, ultrafast perfusion of compounds was achieved with a piezo-driven perfusion system and theta glass (Siskiyou) on to eGFP-expressing cells. The membrane holding potential was $-70 \mathrm{mV}$. All recordings were performed at room temperature using an Axopatch 200B amplifier (Axon Instruments) and signals were filtered at $2 \mathrm{kHz}$ and digitized at $10 \mathrm{kHz}$. For $\alpha 7 \mathrm{nAChRs}$, signals were filtered at $10 \mathrm{kHz}$ with a digitization rate of $50 \mathrm{kHz}$. Data acquisition and subsequent analysis were done with pClamp9 software (Axon Instruments)

Statistics. Results are represented as mean \pm SD unless stated otherwise. All FLIPR assay, immunostaining experiments and radioligand binding assay in HEK293T cells and rat neurons were replicated thrice. Significance analyses between two datasets were performed with nonparametric Mann-Whitney $U$ test, while statistical analyses between three or more datasets used one-way ANOVA (GraphPad Prism, Carlsbad, CA). Significance level $\alpha=0.05$ was set.

Reporting summary. Further information on research design is available in the Nature Research Reporting Summary linked to this article.

\section{Data availability}

Data supporting the findings of this manuscript are available from the corresponding author upon reasonable request. A reporting summary for this Article is available as a Supplementary Information file. The source data underlying Figs. 1b, d; 2b-d; 3b, c, g, i; 5b, c, e; 6b-e; 7c-e and Supplementary Figs. 2b; 3b, c; 4b, c, f; $5 d, e ; 6 b-d$ are provided in the Source Data File. Source data are provided with this paper.

Received: 31 January 2020; Accepted: 15 May 2020;

Published online: 03 June 2020

\section{References}

1. Role, L. W. \& Berg, D. K. Nicotinic receptors in the development and modulation of CNS synapses. Neuron 16, 1077-1085 (1996).

2. Gotti, C. \& Clementi, F. Neuronal nicotinic receptors: from structure to pathology. Prog. Neurobiol. 74, 363-396 (2004).

3. Lindstrom, J. Nicotinic acetylcholine receptors in health and disease. Mol. Neurobiol. 15, 193-222 (1997).

4. Hogg, R. C., Raggenbass, M. \& Bertrand, D. Nicotinic acetylcholine receptors: from structure to brain function. Rev. Physiol., Biochem. Pharmacol. 147, 1-46 (2003).

5. Le Novere, N., Corringer, P. J. \& Changeux, J. P. The diversity of subunit composition in nAChRs: evolutionary origins, physiologic and pharmacologic consequences. J. Neurobiol. 53, 447-456 (2002).

6. Picciotto, M. R. Nicotine as a modulator of behavior: beyond the inverted U. Trends Pharmacol. Sci. 24, 493-499 (2003).

7. Dineley, K. T., Pandya, A. A. \& Yakel, J. L. Nicotinic ACh receptors as therapeutic targets in CNS disorders. Trends Pharmacol. Sci. 36, 96-108 (2015).

8. Hurst, R., Rollema, H. \& Bertrand, D. Nicotinic acetylcholine receptors: from basic science to therapeutics. Pharmacol. Therapeutics 137, 22-54 (2013).

9. Cooper, S. T. \& Millar, N. S. Host cell-specific folding and assembly of the neuronal nicotinic acetylcholine receptor alpha7 subunit. J. Neurochem. 68, 2140-2151 (1997).

10. Kassner, P. D. \& Berg, D. K. Differences in the fate of neuronal acetylcholine receptor protein expressed in neurons and stably transfected cells. $J$. Neurobiol. 33, 968-982 (1997).

11. $\mathrm{Gu}, \mathrm{S}$. et al. Brain alpha7 nicotinic acetylcholine receptor assembly requires NACHO. Neuron 89, 948-955 (2016).

12. Matta, J. A. et al. NACHO mediates nicotinic acetylcholine receptor function throughout the brain. Cell Rep. 19, 688-696 (2017).
13. $\mathrm{Gu}, \mathrm{S}$. et al. alpha6-Containing nicotinic acetylcholine receptor reconstitution involves mechanistically distinct accessory components. Cell Rep. 26, 866-874 e863 (2019)

14. Millar, N. RIC-3: a nicotinic acetylcholine receptor chaperone. $\mathrm{Br}$. J. Pharmacol. 153, S177-S183 (2008).

15. Dawe, G. B. et al. alpha7 nicotinic acetylcholine receptor upregulation by antiapoptotic Bcl-2 proteins. Nat. Commun. 10, 2746 (2019).

16. Changeux, J. P. Nicotine addiction and nicotinic receptors: lessons from genetically modified mice. Nat. Rev. Neurosci. 11, 389-401 (2010).

17. Miller-Fleming, L., Olin-Sandoval, V., Campbell, K. \& Ralser, M. Remaining mysteries of molecular biology: the role of polyamines in the cell. J. Mol. Biol. 427, 3389-3406 (2015).

18. Pegg, A. E. \& Casero, R. A. Jr. Current status of the polyamine research field. Methods Mol. Biol. 720, 3-35 (2011).

19. Turecki, G. The molecular bases of the suicidal brain. Nat. Rev. Neurosci. 15, 802-816 (2014).

20. Nichols, C. G. \& Lee, S. J. Polyamines and potassium channels: a 25-year romance. J. Biol. Chem. 293, 18779-18788 (2018).

21. Williams, K. Interactions of polyamines with ion channels. Biochemical J. 325, 289-297 (1997)

22. Haghighi, A. P. \& Cooper, E. A molecular link between inward rectification and calcium permeability of neuronal nicotinic acetylcholine alpha3beta 4 and alpha4beta2 receptors. J. Neurosci. 20, 529-541 (2000).

23. Muszynski, C. A., Robertson, C. S., Goodman, J. C. \& Henley, C. M. DFMO reduces cortical infarct volume after middle cerebral artery occlusion in the rat. J. Cereb. Blood Flow. Metab. 13, 1033-1037 (1993).

24. Yang, X. et al. A public genome-scale lentiviral expression library of human ORFs. Nat. methods 8, 659-661 (2011).

25. Kachel, H. S., Patel, R. N., Franzyk, H. \& Mellor, I. R. Block of nicotinic acetylcholine receptors by philanthotoxins is strongly dependent on their subunit composition. Sci. Rep. 6, 38116 (2016).

26. Bewley, M. C. et al. Structures of wild-type and mutant human spermidine/ spermine N1-acetyltransferase, a potential therapeutic drug target. Proc. Nat Acad. Sci. USA 103, 2063-2068 (2006).

27. Gerner, E. W. \& Meyskens, F. L. Jr. Polyamines and cancer: old molecules, new understanding. Nat. Rev. Cancer 4, 781-792 (2004).

28. Prince, R. J. \& Sine, S. M. Epibatidine binds with unique site and state selectivity to muscle nicotinic acetylcholine receptors. J. Biol. Chem. 273 7843-7849 (1998)

29. Mandal, S., Mandal, A., Johansson, H. E., Orjalo, A. V. \& Park, M. H Depletion of cellular polyamines, spermidine and spermine, causes a total arrest in translation and growth in mammalian cells. Proc. Natl Acad. Sci. USA 110, 2169-2174 (2013).

30. Morales-Perez, C. L., Noviello, C. M. \& Hibbs, R. E. X-ray structure of the human alpha4beta2 nicotinic receptor. Nature 538, 411-415 (2016).

31. Stokes, C., Treinin, M. \& Papke, R. L. Looking below the surface of nicotinic acetylcholine receptors. Trends Pharmacol. Sci. 36, 514-523 (2015).

32. Tikhonov, D. B., Mellor, I. R. \& Usherwood, P. N. Modeling noncompetitive antagonism of a nicotinic acetylcholine receptor. Biophys. J. 87, 159-170 (2004).

33. Kawai, H. \& Berg, D. K. Nicotinic acetylcholine receptors containing alpha 7 subunits on rat cortical neurons do not undergo long-lasting inactivation even when up-regulated by chronic nicotine exposure. J. Neurochem. $\mathbf{7 8}$, 1367-1378 (2001)

34. Hurst, R. S. et al. A novel positive allosteric modulator of the alpha7 neuronal nicotinic acetylcholine receptor: in vitro and in vivo characterization. J. Neurosci. 25, 4396-4405 (2005).

35. Marubio, L. M. et al. Reduced antinociception in mice lacking neuronal nicotinic receptor subunits. Nature 398, 805-810 (1999).

36. Borlongan, C. V. et al. (-)-nicotine protects against systemic kainic acidinduced excitotoxic effects. Exp. Neurol. 136, 261-265 (1995).

37. Akaike, A., Tamura, Y., Yokota, T., Shimohama, S. \& Kimura, J. Nicotineinduced protection of cultured cortical neurons against N-methyl-D-aspartate receptor-mediated glutamate cytotoxicity. Brain Res. 644, 181-187 (1994)

38. Marin, P., Maus, M., Desagher, S., Glowinski, J. \& Premont, J. Nicotine protects cultured striatal neurones against $\mathrm{N}$-methyl-D-aspartate receptormediated neurotoxicity. Neuroreport 5, 1977-1980 (1994)

39. Dajas-Bailador, F. A., Lima, P. A. \& Wonnacott, S. The alpha7 nicotinic acetylcholine receptor subtype mediates nicotine protection against NMDA excitotoxicity in primary hippocampal cultures through a $\mathrm{Ca}(2+)$ dependent mechanism. Neuropharmacology 39, 2799-2807 (2000).

40. Hejmadi, M. V., Dajas-Bailador, F., Barns, S. M., Jones, B. \& Wonnacott, S Neuroprotection by nicotine against hypoxia-induced apoptosis in cortical cultures involves activation of multiple nicotinic acetylcholine receptor subtypes. Mol. Cell. Neurosci. 24, 779-786 (2003)

41. Kharbanda, S. et al. Role for Bcl-xL as an inhibitor of cytosolic cytochrome C accumulation in DNA damage-induced apoptosis. Proc. Natl Acad. Sci. USA 94, 6939-6942 (1997) 
42. Orrenius, S. \& Zhivotovsky, B. Cardiolipin oxidation sets cytochrome c free. Nat. Chem. Biol. 1, 188-189 (2005).

43. Green, W. N. \& Millar, N. S. Ion-channel assembly. Trends Neurosci. 18, 280-287 (1995).

44. Schwartz, R. D. \& Kellar, K. J. Nicotinic cholinergic receptor binding sites in the brain: regulation in vivo. Science 220, 214-216 (1983).

45. Lester, H. A. et al. Nicotine is a selective pharmacological chaperone of acetylcholine receptor number and stoichiometry. Implic. Drug Discov. AAPS J. 11, 167-177 (2009).

46. Halevi, S. et al. The C. elegans ric-3 gene is required for maturation of nicotinic acetylcholine receptors. EMBO J. 21, 1012-1020 (2002).

47. Tran, P. V., Georgieff, M. K. \& Engeland, W. C. Sodium depletion increases sympathetic neurite outgrowth and expression of a novel TMEM35 genederived protein (TUF1) in the rat adrenal zona glomerulosa. Endocrinology 151, 4852-4860 (2010).

48. Youle, R. J. \& Strasser, A. The BCL-2 protein family: opposing activities that mediate cell death. Nat. Rev. Mol. Cell Biol. 9, 47-59 (2008).

49. Tiveron, M. C. et al. LAMP5 fine-tunes GABAergic synaptic transmission in defined circuits of the mouse brain. PLOS ONE 11, e0157052 (2016).

50. Stromgaard, K. et al. Solid-phase synthesis and biological evaluation of a combinatorial library of philanthotoxin analogues. J. Med. Chem. 43, 4526-4533 (2000).

51. Aizenman, C. D., Munoz-Elias, G. \& Cline, H. T. Visually driven modulation of glutamatergic synaptic transmission is mediated by the regulation of intracellular polyamines. Neuron 34, 623-634 (2002).

52. Fleidervish, I. A., Libman, L., Katz, E. \& Gutnick, M. J. Endogenous polyamines regulate cortical neuronal excitability by blocking voltage-gated $\mathrm{Na}+$ channels. Proc. Natl Acad. Sci. USA 105, 18994-18999 (2008).

53. Herberg, L. J., Rose, I. C., de Belleroche, J. S. \& Mintz, M. Ornithine decarboxylase induction and polyamine synthesis in the kindling of seizures: the effect of alpha-difluoromethylornithine. Epilepsy Res. 11, 3-7 (1992).

54. Takechi, K., Suemaru, K., Kiyoi, T., Tanaka, A. \& Araki, H. The alpha4beta2 nicotinic acetylcholine receptor modulates autism-like behavioral and motor abnormalities in pentylenetetrazol-kindled mice. Eur. J. Pharmacol. 775, 57-66 (2016).

55. Limon, A., Mamdani, F., Hjelm, B. E., Vawter, M. P. \& Sequeira, A. Targets of polyamine dysregulation in major depression and suicide: Activity-dependent feedback, excitability, and neurotransmission. Neurosci. Biobehav. Rev. 66, 80-91 (2016)

56. Sequeira, A. et al. Implication of SSAT by gene expression and genetic variation in suicide and major depression. Arch. Gen. Psychiatry 63, 35-48 (2006).

57. Gandelman, J. A., Newhouse, P. \& Taylor, W. D. Nicotine and networks: Potential for enhancement of mood and cognition in late-life depression. Neurosci. Biobehav. Rev. 84, 289-298 (2018).

58. Peron, A. et al. Snyder-Robinson syndrome: a novel nonsense mutation in spermine synthase and expansion of the phenotype. Am. J. Med. Genet. A 161A, 2316-2320 (2013).

59. Ghasemi, M. \& Hadipour-Niktarash, A. Pathologic role of neuronal nicotinic acetylcholine receptors in epileptic disorders: implication for pharmacological interventions. Rev. Neurosci. 26, 199-223 (2015).
60. Kaasinen, K., Koistinaho, J., Alhonen, L. \& Janne, J. Overexpression of spermidine/spermine $\mathrm{N}$-acetyltransferase in transgenic mice protects the animals from kainate-induced toxicity. Eur. J. Neurosci. 12, 540-548 (2000).

61. Nordberg, A. Nicotinic receptor abnormalities of Alzheimer's disease: therapeutic implications. Biol. Psychiatry 49, 200-210 (2001).

\section{Acknowledgements}

The authors are grateful to Wes Davini for his valuable inputs.

\section{Author contributions}

M.D. and M.L. performed cDNA library screening. J.A.M. conducted electrophysiology experiments. M.D. and H.Y. performed immunocytochemistry assays. M.D. conducted radioligand binding assays. D.K. and S.G. provided chimeric cDNA constructs. M.D. and D.S.B. wrote the manuscript. All authors contributed to the discussion and editing of the paper. D.S.B. supervised the project.

\section{Competing interests}

All contributing authors are full-time employees in Johnson and Johnson.

\section{Additional information}

Supplementary information is available for this paper at https://doi.org/10.1038/s41467020-16629-3.

Correspondence and requests for materials should be addressed to D.S.B.

Peer review information Nature Communications thanks the anonymous reviewers for their contribution to the peer review of this work. Peer reviewer reports are available.

Reprints and permission information is available at http://www.nature.com/reprints

Publisher's note Springer Nature remains neutral with regard to jurisdictional claims in published maps and institutional affiliations.

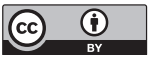

Open Access This article is licensed under a Creative Commons Attribution 4.0 International License, which permits use, sharing, adaptation, distribution and reproduction in any medium or format, as long as you give appropriate credit to the original author(s) and the source, provide a link to the Creative Commons license, and indicate if changes were made. The images or other third party material in this article are included in the article's Creative Commons license, unless indicated otherwise in a credit line to the material. If material is not included in the article's Creative Commons license and your intended use is not permitted by statutory regulation or exceeds the permitted use, you will need to obtain permission directly from the copyright holder. To view a copy of this license, visit http://creativecommons.org/ licenses/by/4.0/.

(C) The Author(s) 2020 